

\section{Sumário}

I. Direito À Saúde e Políticas. 13

As Redes de Atenção à Saúde nos 30 anos do Sistema Único de Saúde: histórias, PROPOSTAS E DESAFIOS

Márcia Araújo Sabino de Freitas e Maria Rizoneide Negreiros de Araújo

DiREITO À SAÚdE PARA O RESIDENTE FRONTEIRIÇO: DESAFIO PARA A INTEGRALIDADE DO SUS .35 Fabrícia Helena Linhares Coelho da Silva Pereira, Livia Maria de Sousa e Tarin Cristino Frota Mont Alverne

Medidas provisórias e políticas públicas: Uma análise do PaPEl do Congresso NaCiOnal NAS POlíticas de SAÚde nO GOVERno Dilma $(2011-2016)$............................................55

Clóvis Alberto Bertolini de Pinho

Os LIMITES E A EXTENSÃo DA DEFESA DE DIREITOS FUNDAMENTAIS POR MEIO DE INSTRUMENTOS PROCESSUAIS DE COGNIÇÃo ESTREITA: MANDAdO DE SEGURANÇA E O CASO DA SAÚDE ...............76 Héctor Valverde Santana e Roberto Freitas Filho

DESENHANdo MOdElos de SISTEMAS de DISPUTAS PARA A ADMINISTRAÇÃo PÚbliCA: PROPOSIÇÕES ACERCA DA POLÍTICA PÚBLICA DE FORNECIMENTO DE MEDICAMENTOS PELO VIÉS DO DIÁLOGO INSTITUCIONAL

Mônica Teresa Costa Sousa e Maíra Lopes de Castro

O ACCOUNTABILITY DO SERVIÇO PÚBlico DE SAÚdE E A ATUAÇÃo INSTITUCIONAL NO ESTADO DO CEARÁ. 125 Mariana Dionísio de Andrade, Beatriz de Castro Rosa e Eduardo Régis Girão de Castro Pinto

Privacidade Relacional no ambulatório de oncogenética do hospital de Clínicas de Porto Alegre 146

Leonardo Stoll de Morais, Patrícia Ashton-Prolla, José Roberto Goldim e Márcia Santana Fernandes

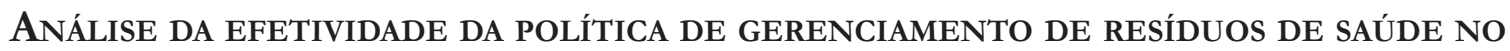
Município de SANTOS 175

Renato Braz Mehanna Khamis, Lígia Maria Comis Dutra e Thays Costa Nostre Teixeira

II. Direito À Saúde e Judicialização

Atuação da Defensoria Pública para a garantia do direito à saúde: A judicialização COMO INSTRUMENTO DE ACESSO À SAÚDE 195 Ramiro Nóbrega Sant'Ana 
A Judicialização do aCesso aos medicamentos em Belo Horizonte: UMA QUESTão sobre EQUIDADE.

Kammilla Éric Guerra de Araújo e Carlota Quintal

THE COURTS AND THE DELIVERY OF MEDICINES BY UNIFIED HEALTH SYSTEM IN BRAZIL: RECENT DEVELOPMENTS IN A DIFFICULT RELATIONSHIP BETWEEN JUDGES AND POLICY-MAKERS. 237 Eduardo Rocha Dias e Gina Vidal Marcílio Pompeu

Direito, SAÚde E SUICÍDIO: IMPACTOS DAS LEIS E DECISÕES JUDiCiAIS NA SAÚdE DOS JOVENS LGBT

Bruno Rafael Silva Nogueira Barbosa e Robson Antão de Medeiros

A Desproteção À SAÚde do TRABALHAdor e SUA JUdicialização Renata Salgado Leme e Luiz Pinto de Paula Filho

A judicialização da saúde sob o olhar da Análise Econômica do Direito: um exame dos INCENTIVOS AO AJUIZAMENTO E À SOLUÇÃo EXTRAJUdiCiAL DE CONFLITOS ..........................308 Victor Aguiar de Carvalho

III. Direito À SAúde e as Instituições de REgulação

A regulação da saúde Suplementar no Brasil: Perspectivas e ameaÇaS 329 Carlos Marden Cabral Coutinho e Taís Vasconcelos Cidrão

Os Mecanismos de Participação da Agência Nacional de Saúde Suplementar (ANS)343 Natasha Schmitt Caccia Salinas e Fernanda Martins

Papel institucional dos canais de reclamação para a Resolução extrajudicial de CONFLITOS SOBRE PLANOS DE SAÚDE: UMA ANÁLISE COMPARADA

Rafaela Magalhães Nogueira Carvalho, Antônio José Maristrello Porto e Bruno Araujo Ramalho

MedicAmentos SEM REgistros NA ANVISA: UMA ABORDAGEM INSTITUCIONAL .395 Igor De Lazari, Sergio Dias e Carlos Bolonha

A SUSTENTABILIDADE ECONÔMICO-FINANCEIRA DAS OPERADORAS DE PLANOS DE SAÚDE DIANTE DA CONCESSÃo INDISCRIMINADA DE TUTELAS DE URGÊNCIA NO BRASIL. 410 Álisson José Maia Melo e Nathalia Aparecida Sousa Dantas

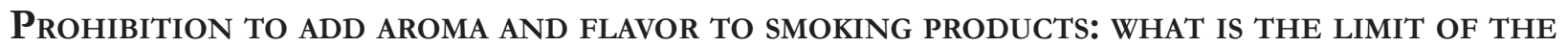
Regulatory power of the Brazilian Health Regulatory Agency? 435 Joedson de Souza Delgado e Ivo Teixeira Gico Júnior 


\title{
Papel institucional dos canais de reclamação para a resolução extrajudicial de conflitos sobre planos de saúde: uma análise comparada*
}

\author{
Institutional role of complaint channels \\ for settlement of conflicts about health \\ insurance plans: a comparative analysis
}

\author{
Rafaela Magalhães Nogueira Carvalho** \\ Antônio José Maristrello Porto*** \\ Bruno Araujo Ramalho****
}

\section{Resumo}

Litígios sobre planos de saúde são responsáveis por grande volume dos processos que tramitam nos tribunais brasileiros. Assim, os métodos alternativos para solução de conflitos são ferramentas que devem ser fortalecidas e aperfeiçoadas para minimizar os efeitos danosos da chamada "judicialização da saúde". Sob tal justificativa, o presente trabalho teve o objetivo de investigar diferentes aspectos presentes em dois importantes canais de reclamações sobre planos de saúde: consumidor.gov.br e atendimento da Agência Nacional de Saúde Suplementar (ANS TabNet). A pesquisa contemplou as queixas que ingressaram em ambas as plataformas no intervalo entre os meses de maio de 2014 a maio de 2018. Como resultados, foram observadas importantes semelhanças, tais como a distribuição de reclamações por região geográfica e a grande concentração de reclamações atribuídas a poucas operadoras. A principal diferença entre as plataformas está na quantidade de queixas processadas - 6.604 para o consumidor.gov.br e 385.020 para o canal da agência reguladora - e nos temas tratados - o canal do consumidor recebe maior volume relacionado a cobranças indevidas e problemas de atendimento com o SAC, enquanto parcela substancial das reclamações tratadas pelo canal da ANS versa sobre a garantia de coberturas assistenciais. No âmbito da discussão, foram especuladas algumas hipóteses para explicar por que os canais extrajudiciais, isoladamente, não são suficientes para conter a escalada crescente da judicialização dos planos de saúde, tais como: a maior acessibilidade dos órgãos do Poder Judiciário; o imediatismo das decisões liminares; e o conteúdo favorável de algumas decisões judiciais. Concluiu-se que ambas as plataformas exercem um papel relevante para a resolução de conflitos no setor e, em alguma medida, exercem papéis complementares entre si.

Palavras-chave: Resolução extrajudicial de conflitos. Planos de saúde. Judicialização.

Bacharel em Direito pela Universidade Federal do Estado do Rio de Janeiro (UniRio) Mestre em Direito da Regulação pela FGV/RJ. Email : brunrama@hotmail.com.

Recebido em 25/09/2018

** Professora e pesquisadora da FGV DIREITO RIO. E-mail : rafaela.nogueira@fgv.br.

*** Coordenador do Centro de Pesquisa em Direito e Economia (CPDE) e Professor da FGV DIREITO RIO. E - mail: antonio.maristrello@fgv.br. 


\section{Abstract}

Conflicts about health plans are responsible for a large volume of lawsuits in Brazilian courts. Thus, alternative methods for dispute resolution are tools that need to be strengthened and improved to minimize the harmful effects of so-called "health judicialization". Under this point of view, the present work had the objective of investigating different aspects presented in two of the main channels of out-of-court dispute resolution in the health insurance marketplace: consumidor.gov.br and the complaints channel of the National Regulatory Agency for Private Health Insurance and Plans (ANS). The survey contemplated the complaints registered in both platforms in the period between May 2014 and May 2018. As results, important similarities were observed, such as the distribution of complaints by geographic region and the great concentration of complaints related to few insurance companies. The main difference between the platforms is the number of complaints processed - 6,604 for the consumidor.gov.br and 385,020 for the channel of the regulatory agency - and the subjects treated - the consumer channel receives more volume related to undue charges and information services, while a substantial portion of the complaints handled by the ANS channel refers to the guarantee of care cover. Some hypotheses were speculated to explain why the channels, alone, are not enough to contain the growing escalation of the judicialization of health plans, such as: greater accessibility of institutions of the Judiciary; the immediacy of judicial injunctions; and the favorable content of some judicial decisions. It was concluded that both platforms play a relevant role in the resolution of conflicts in the sector and, to some extent, play complementary roles among themselves.

Keywords: Out-of-court dispute resolution. Health insurance plans. Judicialization.

\section{INTRODUÇÃo}

De acordo com o Anuário da Justiça São Paulo ${ }^{1}$, os planos de saúde ultrapassaram os serviços bancários no ranking de temas mais julgados pela seção de direito privado do Tribunal de Justiça de São Paulo (TJSP) em 2017, registrando alta de 15\% em relação a 2016. Além disso, a maioria das ações da área de saúde que chega à seção de direito público é julgada favoravelmente ao consumidor².

A regulação do setor de saúde suplementar tem como marcos legais a Lei nº 9.656 , de 03 de junho de 1998, que dispõe sobre os planos e seguros privados de assistência à saúde, e a Lei ñ 9.961, de 28 de janeiro de 2000, que criou a Agência Nacional de Saúde Suplementar (ANS). Como a normatização regulatória ainda é complementada por resoluções da agência reguladora, vislumbra-se uma complexa rede de direitos e deveres a serem tutelados.

Em linhas gerais, a regulação da ANS estabelece diferentes modalidades de regime de contratação: (i) individual ou familiar, (ii) coletivo empresarial e (iii) coletivo por adesão. Para cada uma destas formas de contratação, há tratamentos jurídicos significativamente distintos.

Caracteriza-se como plano de saúde "individual ou familiar" aquele que oferece cobertura para livre adesão de beneficiários - pessoas naturais que podem apresentar-se com ou sem grupo familiar interessado no serviço. Tal modalidade é marcada pelo livre ingresso dos beneficiários em sua cobertura, o que acarreta maior heterogeneidade no perfil de seus contratantes.

De outra banda, os planos coletivos são aqueles em que se exige a vinculação a algum grupo populacional. O plano coletivo "empresarial” é aquele ofertado por uma empresa aos seus funcionários, ou seja, é

1 CONJUR. Conjur transmite lançamento do Anuário da Justiça São Paulo 2018. Disponível em https://www.conjur.com.br/2018ago-15/conjur-transmite-lancamento-anuario-justica-sao-paulo2018. Acesso em: 17 ago. 2018.

2 PLANO de saúde lideram ranking de julgamentos de SP em 2017. Disponível em https://veja.abril.com.br/economia/planosde-saude-lideram-ranking-de-julgamentos-de-sp-em-2017/. Acesso em 17 de ago. de 2018. 
o plano viabilizado para um conjunto de beneficiários que trabalham na mesma empresa, enquanto que o plano coletivo "por adesão" se destina aos grupos de pessoas que, de comum entre si, têm uma categoria profissional ou outro vínculo jurídico que justifique sua reunião em uma mesma instituição.

Ao contrário dos planos individuais, que possuem maior rigidez regulatória dada pela própria lei dos planos de saúde (Lei n ${ }^{\circ}$ 9656/98) e pela ANS, os planos coletivos contam com mais flexibilidade contratual - notadamente no que concerne ao reajuste anual por variação de custos e ao formato de rescisão unilateral do contrato. Sendo o mercado dinâmico e reativo a incentivos, o perfil dos contratos foi se modelando progressivamente de forma a confluir para o "lado" com menor rigidez regulatória (vínculos coletivos).

Assim, por se tratar de um nicho econômico com diferentes produtos e diferentes formas de contratação, é de se esperar que o perfil das reclamações apresente uma variabilidade de circunstâncias. Portanto, a análise das bases de dados que contemplam as queixas do setor pode ser de valiosa utilidade para a melhor compreensão dos problemas que lhe são correlatos.

Dentre os canais de resolução de conflitos atualmente disponíveis, merecem destaque o canal "consumidor.gov", criado pela Secretaria Nacional do Consumidor, e o canal de atendimento ao consumidor disponibilizado pela ANS. Ambos possuem abrangência nacional e disponibilizam publicamente as informações referentes ao conteúdo das reclamações que lhes são apresentadas.

Considerando que tais canais de atendimento favorecem a resolução de conflitos sem a necessidade de postular em juízo, o objetivo deste artigo é mapear alguns atributos específicos das reclamações de usuários em ambos canais de atendimento (consumidor.gov.br e ANS), de modo a comparar os resultados e discutir o protagonismo das instâncias de resolução extrajudicial de conflitos no contexto da judicialização da saúde.

Espera-se que a pesquisa possa enriquecer a literatura que versa sobre a judicialização da saúde e permita revelar aspectos importantes relacionados às reclamações que são tratadas pelas diferentes instituições de resolução extrajudicial de conflitos e, a partir daí, contribuir para o debate sobre o protagonismo destes serviços enquanto meio hábil para a redução dos litígios judiciais.

\section{Metodologia de extração e Categorização dos dados}

Definiu-se como período de extração dos dados o intervalo entre os meses de maio de 2014 a maio de 2018. Os dados inicialmente foram extraídos da base disponibilizada pelo canal consumidor.gov.br. ${ }^{3}$

$\mathrm{Na}$ sequência, realizou-se o acesso no sítio eletrônico da ANS, onde são disponibilizados os pedidos de informação e os registros de reclamações a partir da base denominada ANS TabNet ${ }^{4}$. Trata-se de uma ferramenta desenvolvida pelo Datasus - MS e cujo objetivo central é possibilitar a tabulação dos dados dos diversos sistemas de informação da ANS.

A partir da categorização trazida pela base de dados do consumidor.gov, realizou-se um agrupamento semelhante dos dados colhidos a partir do ANS Tabnet, de maneira a dar-lhes o maior paralelismo possível. Desta feita, foram selecionadas apenas "reclamações" disponíveis no ANS Tabnet, descartando-se a opção que contempla a consulta para "pedidos de informação" registrados perante a agência reguladora.

Cada uma das categorias foi quantificada levando-se em conta o quantitativo de reclamações em números absolutos e números relativos (percentuais).

3 Disponível em https://www.consumidor.gov.br/pages/dadosabertos/externo/. Acesso em 17 de setembro de 2018.

4 O “ANS Tabnet" permite a realização de diversos tipos de consultas sobre beneficiários, operadoras, planos privados de saúde, ressarcimento ao SUS e demandas do consumidor pelo acesso a diversos sistemas de informações da ANS. Estão disponíveis para consultas os dados a partir de março de 2000, em intervalos de atualização trimestral. A base é disponibilizada em: <http://www. ans.gov.br/anstabnet/index.htm>. Acesso em: 13 ago. 2018. 


\section{ANálise comparada entre os diferentes CANAIS de ReCLAmações}

Antes de se examinar os aspectos quantitativos e qualitativos relacionados às reclamações do portal consumidor.gov.br e do canal de atendimento da ANS, é imperioso destacar algumas particularidades de cada um destes serviços.

O consumidor.gov.br é uma plataforma digital gratuita e de utilidade pública que tem como objetivo estimular a solução consensual de conflitos consumeristas, sendo um meio de resolução administrativa em alternativa à via judicial. O portal é monitorado e gerenciado conjuntamente pela Secretaria Nacional do Consumidor - Ministério da Justiça e Cidadania -, Procons, Defensorias Públicas, Ministérios Públicos e Tribunais de Justiça.

Uma das principais utilidades desta plataforma online é figurar como alternativa de autocomposição de litígios consumeristas, que integram quase a metade de todos os processos que tramitam perante o sistema judiciário brasileiro ${ }^{5}$.

O processo de funcionamento do canal ocorre de forma simples. Primeiro, o consumidor verifica se a empresa está cadastrada no site. O consumidor registra sua reclamação e a empresa tem até 10 dias para analisar e responder. Em seguida, o consumidor tem até 20 dias para comentar e avaliar a resposta da empresa, informando se sua reclamação foi 'Resolvida' ou 'Não Resolvida', e ainda indicar seu nível de satisfação com $\mathrm{o}$ atendimento recebido.

De forma diversa do consumidor.gov.br, que recepciona as queixas de consumidores sobre produtos e serviços de diferentes setores, o canal de atendimento da ANS é exclusivamente dedicado aos pedidos de informação e ao registro de reclamações relacionadas ao setor de planos de saúde. Para tanto, além do atendimento presencial, disponibiliza-se dois acessos principais para a efetivação do contato: um canal telefônico gratuito (que conta com atendentes treinados para recepcionar a queixa) e uma plataforma digital.

Em seu escopo de atuação, o canal da ANS revela-se como fonte mais específica e conta com a análise de pessoas com maior expertise técnica e exclusivamente dedicados à regulação do setor de saúde suplementar ${ }^{6}$.

\subsection{Panorama quantitativo das reclamações}

Comparando o total de reclamações submetidas a cada um dos canais de atendimento, foi possível identificar diferenças quantitativas importantes.

Para o período estudado 7 , foram recepcionadas 6.604 reclamações pelo canal consumidor.gov.br, cuja distribuição anual encontra-se descrita na tabela abaixo.

5 FREITAS, Andrea; XAVIER, Luiza; CASEMIRO, Luciana. Ações de consumo somam quase a metade dos 90 milhões de processos no Judiciário. Disponível em: https://oglobo.globo.com/economia/defesa-do-consumidor/acoes-de-consumo-somam-quase-metadedos-90-milhoes-de-processos-no-judiciario-10266371\#ixzz4Kph8Neud. Acesso em: 30 ago. 2018.

6 O formato de recepção e processamento das reclamações junto à ANS será explicado resumidamente mais à frente.

7 Como exposto na seção introdutória deste artigo, o período de corte adotado para a extração das informações em ambas as bases de dados foi o intervalo de 01/05/2014 a 31/05/2018. 
Tabela 1 - Reclamações consumidor.gov.br (total por ano)

\begin{tabular}{|c|c|c|}
\hline \multicolumn{3}{|c|}{ Reclamações consumidor.gov } \\
\hline Ano & Total & $\%$ \\
\hline 2014 & 218 & $3,30 \%$ \\
\hline 2015 & 1.009 & $15,28 \%$ \\
\hline 2016 & 1.731 & $26,21 \%$ \\
\hline 2017 & 2.596 & $39,31 \%$ \\
\hline 2018 & 1.050 & $15,90 \%$ \\
\hline
\end{tabular}

$\mathrm{N}=6.604$

Fonte: Elaboração Própria (consumidor.gov.br)

Nota-se que existe uma discrepância na quantidade de reclamações entre os anos de 2016 e 2017 em relação aos outros anos. Esta disparidade deve-se, provavelmente, à progressiva notoriedade do site, haja vista que a ferramenta teve seu início bem recente, somente em 2014. Como o ano de 2018 não engloba todos os meses, ainda não há como compará-lo aos anos que lhe antecedem.

Quando confrontamos tais números com o quantitativo de reclamações registradas perante o atendimento da ANS, percebe-se que o volume de consumidores atendidos pela agência reguladora é substancialmente maior: no mesmo período, observou-se um total de 385.020 reclamações recepcionadas - uma superação de cerca de 583\%. Como exposto na tabela abaixo, o registro anual contabilizado para os anos de 2015, 2016 e 2017 oscilou aproximadamente entre 90 a 100 mil reclamações.

Tabela 2 - Reclamações no canal de atendimento ANS (total por ano)

\begin{tabular}{|c|c|c|}
\hline \multicolumn{3}{|c|}{ Reclamações ANS } \\
\hline Ano & Total & $\%$ \\
\hline 2014 & 60.839 & $15,80 \%$ \\
\hline 2015 & 102.629 & $26,66 \%$ \\
\hline 2016 & 90.397 & $23,48 \%$ \\
\hline 2017 & 90.438 & $23,49 \%$ \\
\hline 2018 & 40.717 & $10,58 \%$ \\
\hline
\end{tabular}

$\mathrm{N}=385.020$

Fonte: Elaboração própria (ANS Tabnet).

A diferença quantitativa possivelmente se deve ao maior grau de conhecimento do canal da ANS (se comparado ao consumidor.gov.br), uma vez que a ferramenta existe há muito mais tempo e tem grande utilidade para o registro de Notificações de Intermediação Preliminar (NIPs) - ponto que será discutido mais adiante. Ademais, a existência de uma modalidade de atendimento telefônico, diferentemente da plataforma do consumidor.gov, também permite uma maior absorção de queixas, especialmente daqueles consumidores idosos ou com algum tipo de dificuldade para o uso de ferramentas digitais.

Para além das reclamações, é importante destacar que a agência reguladora também presta esclarecimentos e tira dúvidas a partir dos atendimentos categorizados como "pedidos de informação". Trata-se, a propósito, do maior volume de registros, perfazendo um total de 1.071.478 (um milhão, setenta e um mil e quatrocentos e setenta e oito) "pedidos de informação". Como o foco deste artigo são as queixas de consumidores, optou-se pela utilização tão somente da base de "reclamações".

\subsection{Reclamações por região geográfica}


Em ambos os canais de atendimento, a região Sudeste é a que concentra o maior volume das reclamações, correspondendo a aproximadamente $60 \%$ do total. Os canais também coincidem na contabilização da região Nordeste como aquela que apresenta o segundo maior volume de queixas - perfazendo $17,2 \%$ do total no canal consumidor.gov.br e $19,7 \%$ do total no canal da ANS.

A tabela a seguir ilustra a distribuição das reclamações por região geográfica em ambas as plataformas:

Tabela 3 - Reclamações por região geográfica

\begin{tabular}{|l|c|c|c|}
\hline \multicolumn{4}{|c|}{ Proporção de reclamações por região } \\
\hline \multirow{2}{*}{\multicolumn{1}{c}{ Região }} & \multicolumn{2}{|c|}{ Consumidor.gov } & ANS \\
\cline { 2 - 4 } & Planos de saúde & Geral & Total \\
\hline \multirow{2}{*}{ Sudeste } & $60,3 \%$ & $49,7 \%$ & $64,6 \%$ \\
\hline Nordeste & $17,2 \%$ & $16,3 \%$ & $19,7 \%$ \\
\hline Sul & $12,8 \%$ & $20,7 \%$ & $6,1 \%$ \\
\hline Centro-Oeste & $8,1 \%$ & $9,7 \%$ & $7,3 \%$ \\
\hline Norte & $1,5 \%$ & $3,6 \%$ & $2,0 \%$ \\
\hline
\end{tabular}

Fonte: Elaboração própria (Consumidor.gov e ANS Tabnet)

Ao compararmos o universo geral das reclamações feitas na plataforma consumidor.gov com aquelas que somente versam sobre planos de saúde nesse mesmo canal, podemos notar que há uma disparidade de registros entre algumas regiões. A região Sudeste contabiliza 49,7\% das reclamações totais, o que é inferior aos $60,3 \%$ das reclamações relacionadas a planos de saúde na respectiva região.

A preponderância da região Sudeste certamente se deve ao volume de usuários do setor nos Estados de São Paulo e Rio de Janeiro. Na plataforma consumidor.gov.br, São Paulo é o estado que mais reclama sobre planos de saúde, resultando em 38,99\% das reclamações. O estado do Rio de Janeiro vem em segundo, com 15,94\% das reclamações, seguido do Paraná com 9,40\%, Distrito Federal com 5,80\% e Bahia com 5,56\%.

Tabela 4 - Reclamações consumidor.gov.br por UF do reclamante

\begin{tabular}{|l|c|c|}
\hline \multicolumn{3}{|c|}{ Consumidor.gov: estados que mais reclamam } \\
\hline Estados & Planos de Saúde & Geral \\
\hline São Paulo & $28,99 \%$ & $28,20 \%$ \\
\hline Rio de Janeiro & $15,94 \%$ & $10,52 \%$ \\
\hline Paraná & $9,40 \%$ & $10 \%$ \\
\hline Distrito Federal & $5,80 \%$ & $3,50 \%$ \\
\hline Bahia & $5,56 \%$ & $5,74 \%$ \\
\hline Ceará & $4,30 \%$ & $3,38 \%$ \\
\hline Minas Gerais & $3,86 \%$ & $8,64 \%$ \\
\hline Pernambuco & $4,01 \%$ & $2,43 \%$ \\
\hline Outros & $12,14 \%$ & $27,59 \%$ \\
\hline
\end{tabular}

$\mathrm{N}=6.604$

Fonte: Elaboração Própria (consumidor.gov.br). 
Quando analisamos a base de reclamações da ANS, os Estados de São Paulo e Rio de Janeiro apresentam percentuais bem semelhantes aos descritos pela plataforma do consumidor.gov.br. Também é possível observar um maior protagonismo dos Estados de Pernambuco e de Minas Gerais em comparação aos registros veiculados pelo portal do consumidor.

Tabela 5 - Reclamações ANS por Unidade da Federação

\begin{tabular}{|l|c|c|}
\hline \multicolumn{3}{|c|}{ ANS: estados que mais reclamam } \\
\hline \multicolumn{1}{|c|}{ Estados } & Total & $\%$ \\
\hline São Paulo & 140.344 & $36,5 \%$ \\
\hline Rio de Janeiro & 74.182 & $19,3 \%$ \\
\hline Pernambuco & 29.620 & $7,7 \%$ \\
\hline Minas Gerais & 27.743 & $7,2 \%$ \\
\hline Bahia & 22.233 & $5,8 \%$ \\
\hline Distrito Federal & 19.037 & $4,9 \%$ \\
\hline Paraná & 11.666 & $3,0 \%$ \\
\hline Ceará & 9.056 & $2,4 \%$ \\
\hline Outros & 51.139 & $13,3 \%$ \\
\hline
\end{tabular}

$\mathrm{N}=385.020$

Fonte: Elaboração própria (ANS Tabnet).

\subsection{Distribuição das reclamações por idade}

Com relação ao perfil etário dos reclamantes no canal consumidor.gov, a principal faixa etária é entre 31 e 40 anos, que perfaz 37,67\% das reclamações.

Tabela 6 - Faixa etária dos reclamantes

\begin{tabular}{|l|c|c|}
\hline \multicolumn{2}{|c|}{ Consumidor.gov: faixa etária dos reclamantes } \\
\hline Faixa etária & Planos de saúde & Geral \\
\hline Até $\mathbf{2 0}$ anos & $1,2 \%$ & $2,9 \%$ \\
\hline Entre $\mathbf{2 1}$ e $\mathbf{3 0}$ anos & $23,0 \%$ & $32,3 \%$ \\
\hline Entre $\mathbf{3 1}$ e $\mathbf{4 0}$ anos & $37,7 \%$ & $32,2 \%$ \\
\hline Entre 41 e 50 anos & $18,5 \%$ & $15,4 \%$ \\
\hline Entre 51 e 60 anos & $12,1 \%$ & $10,0 \%$ \\
\hline Entre 61 e 70 anos & $5,2 \%$ & $5,1 \%$ \\
\hline Mais de 70 anos & $2,3 \%$ & $2,1 \%$ \\
\hline
\end{tabular}

$$
\mathrm{N}=6.604
$$

Fonte: Elaboração própria (Consumidor.gov).

É interessante notar que a faixa etária com o maior volume de reclamações sobre planos de saúde é justamente a faixa etária de 31 a 40 anos, o que parece refletir o maior protagonismo deste extrato nas apólices de planos de saúde ${ }^{8}$. Trata-se do intervalo que corresponde à população economicamente ativa e, como tal,

8 Diferentemente do canal da ANS, que estratifica os reclamantes entre interlocutor (aquele que registra a queixa) e beneficiário (aquele que foi vítima do fato reclamado), a base do consumidor.gov.br identifica apenas um reclamante. Portanto, parte-se da prem- 
tem maior propensão a estar associados a um contrato empresarial - tipo de contratação que corresponde a $80 \%$ (oitenta por cento) do mercado?.

Embora a base de dados disponibilizada pelo ANS TabNet não contemple variáveis relativas à faixa etária ou à data de nascimento dos reclamantes, há apontamentos na literatura sobre a maior proporção das reclamações dos beneficiários idosos perante a agência reguladora.

Nesse sentido é a pesquisa desenvolvida por Wilson Marques Vieira Junior e Mônica Martins, que examinou o perfil etário dos usuários que ingressaram com reclamações na ANS no triênio entre 2010 a 2012. Os autores concluíram que os idosos representam uma maior proporção de reclamações se comparada aos usuários mais jovens ${ }^{10}$.

Assim, considerando as evidências relacionadas à maior proporção de reclamações dos beneficiários idosos quando relacionadas ao volume que eles representam sob o total, é de se esperar que este padrão se agrave com o passar dos anos, haja vista o envelhecimento populacional que se projeta para as próximas décadas. Conforme se vê no gráfico que se segue, os idosos corresponderão a mais da metade da população até 2030:

Gráfico 1 - Evolução dos grupos etários - projeção até 2050.

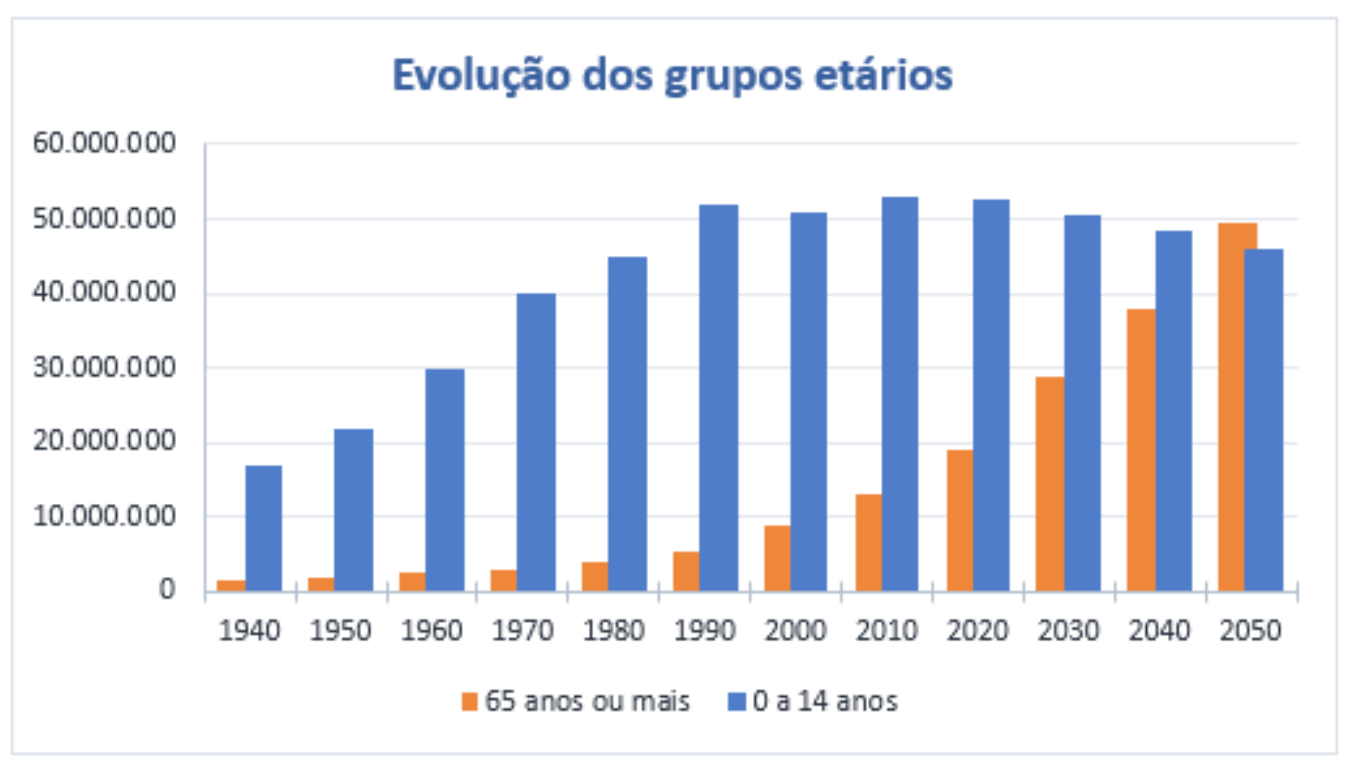

Fonte: BRITO, Fausto. A transição demográfica no Brasil: as possibilidades e os desafios para a economia e a sociedade / Fausto Brito. - Belo Horizonte: UFMG/Cedeplar, 2007 (Texto para discussão 318), p. 13.

\footnotetext{
issa que os reclamantes registrados no portal do consumidor são os próprios usuários do serviço.

9 Segundo o Caderno de Informações da ANS, os planos coletivos empresariais integram 66,4\% de todos os beneficiários de planos de saúde do Brasil, acrescentando-se o percentual de 13,6\% dos beneficiários que possuem planos coletivos por adesão. Juntos, os planos coletivos correspondem a 80\% dos consumidores brasileiros. AGÊNCIA NACIONAL DE SAÚDE SUPLEMENTAR - Caderno de informação da saúde suplementar: beneficiários, operadoras e planos. 2017. Disponível em: <http://www.ans.gov.br/images/ stories/Materiais_para_pesquisa/Perfil_setor/Caderno_informacao_saude_suplementar/caderno_informacao_junho_2017.pdf>. Acesso em: 20 ago. 2018.

10 O estudo examinou o universo de reclamações que ingressaram no canal da ANS no triênio entre 2010 a 2012 apenas para os usuários da região Sudeste. Para examinar a proporção das reclamações com relação à fatia de usuários que existem para a faixa etária respectiva, o autor utilizou como métrica um "coeficiente de reclamações por beneficiários", que corresponde à divisão entre o número de reclamações daquela faixa etária dividida pelo número de beneficiários que correspondem à mesma faixa, multiplicado por 10.000. Como resultado, verificou-se que das 92.235 reclamações analisadas, o coeficiente de reclamações, considerando todo o triênio estudado, foi 60,8 reclamações/10.000 beneficiários idosos, contra 31,1 reclamações/10.000 beneficiários da faixa etária de 20-59 anos. Em todos os anos, a proporção de reclamações de idosos foi maior, proporcionalmente, do que aquela para beneficiários mais jovens. VIEIRA JUNIOR, Wilson M; MARTINS, Mônica. Idosos e planos de saúde no Brasil: análise das reclamações recebidas pela Agência Nacional de Saúde Suplementar. Ciência \& Saúde Coletiva, Rio de Janeiro, v. 20, n. 12, p. 3817-3826, 2015.
} 
O Gráfico 2, por sua vez, corrobora tal previsão ao ilustrar o progressivo envelhecimento populacional no Brasil, segundo dados do Banco Mundial. Em 2015, a expectativa de vida do brasileiro médio era de 75,2 anos, ao passo que, em 2000, a expectativa de vida era apenas de cerca de 70 anos. Ou seja, em 15 anos a expectativa de vida cresceu mais do que 5 anos.

Gráfico 2 - expectativa de vida do brasileiro (1960-2016)

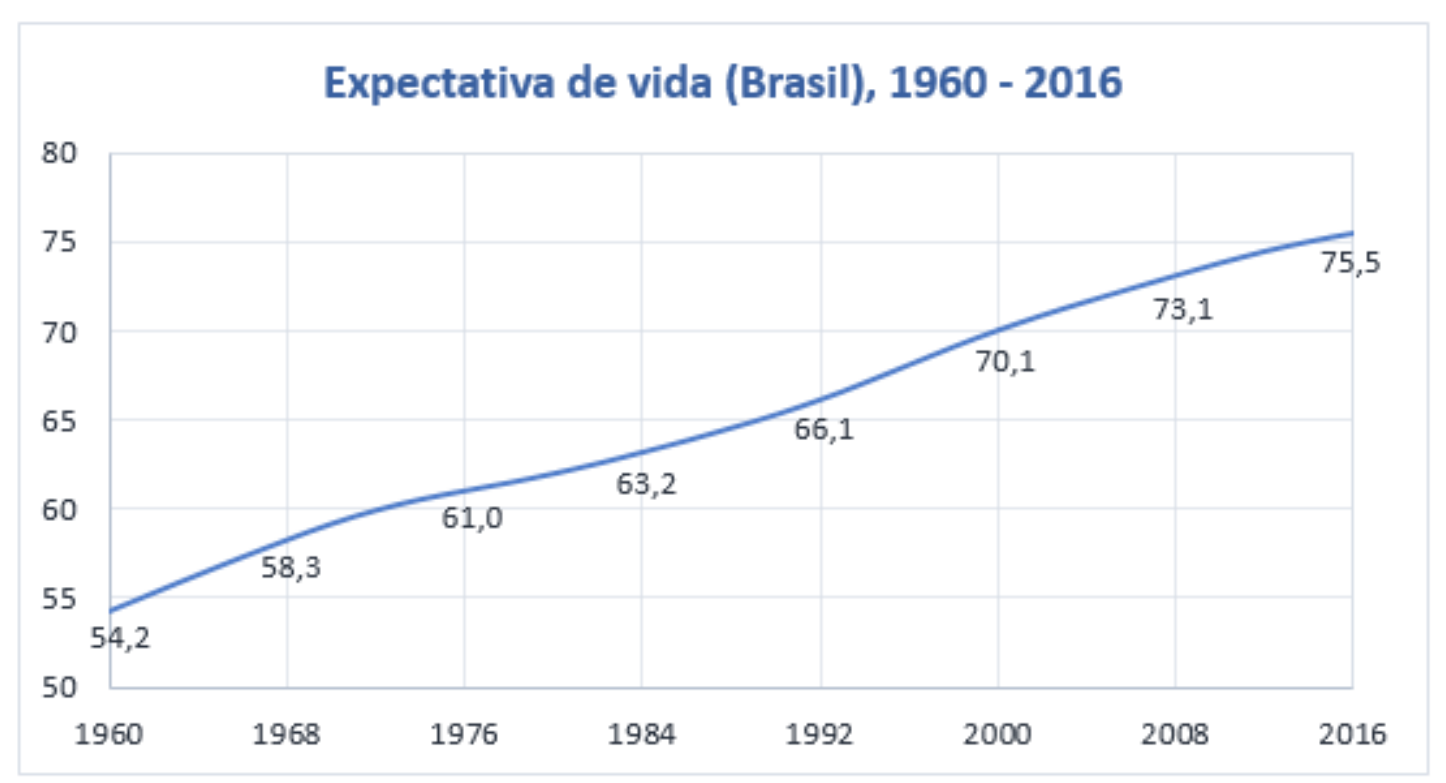

Fonte: Banco Mundial ${ }^{11}$

\subsection{Distribuição das reclamações por operadora}

Quando examinamos a distribuição das reclamações por operadora, verifica-se o quão concentradas são as queixas. No canal consumidor.gov.br, apenas duas operadoras concentram $50 \%$ do total de reclamações, enquanto no canal da ANS o mesmo percentual é atribuído a 10 (dez) empresas sob a regulação da autarquia.

Tabela 7 - Distribuição das reclamações do consumidor.gov.br, por operadora

\begin{tabular}{|l|c|}
\hline \multicolumn{2}{|c|}{$\begin{array}{c}\text { Consumidor.gov: empresas } \\
\text { mais reclamadas }\end{array}$} \\
\hline Amil & $34,80 \%$ \\
\hline Bradesco Saúde & $16,34 \%$ \\
\hline Unimed & $9,45 \%$ \\
\hline SulAmérica Saúde & $6,83 \%$ \\
\hline Outros & $32,58 \%$ \\
\hline
\end{tabular}

$\mathrm{N}=6.604$

Fonte: Elaboração Própria (consumidor.gov.br)

Curiosamente, o canal de reclamações da ANS apresenta quase a mesma ordem de classificação no tocante às quatro operadoras "mais reclamadas" (descritas na Tabela 7). A empresa Unimed Rio não está cadastrada no site consumidor.gov, e de acordo com o canal de reclamações da ANS, a Unimed Rio estaria em terceiro lugar como mais reclamada. Portanto, os dados são similares, mas não idênticos. Embora a

11 BANCO MUNDIAL. Brazil. Disponível em: https://data.worldbank.org/country/brazil?locale=pt. Acesso em: 19 nov. 2018. 
distribuição percentual das queixas seja mais diluída no canal de atendimento da agência reguladora, há uma considerável concentração das reclamações em poucas empresas reguladas, eis que apenas 10 (dez) convênios respondem por aproximadamente $50 \%$ das 385.020 reclamações.

Gráfico 3 - Concentração do número de reclamações por operadora (ANS)

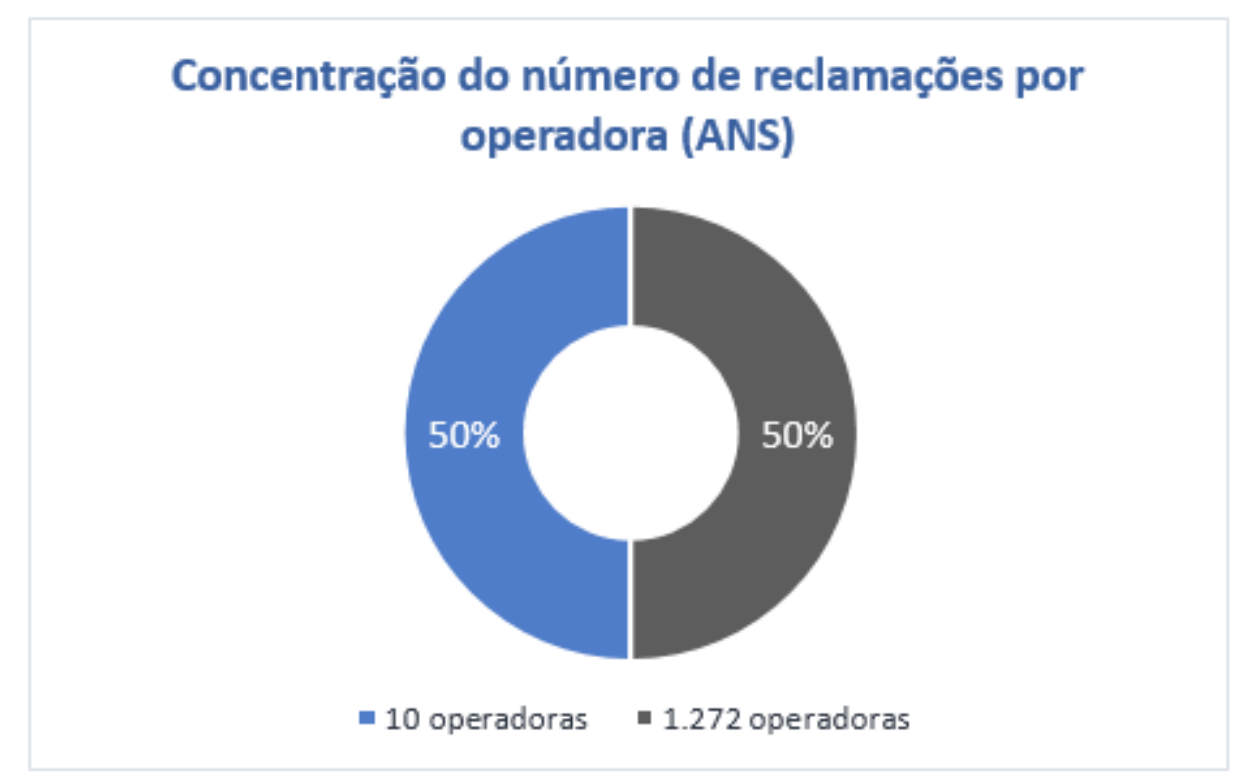

Fonte: Elaboração própria (ANS Tabnet).

Segundo Carlos Ocké-Reis, o mercado brasileiro de saúde suplementar possui um perfil oligopolizado, o que impõe desafios para lidar com a regulação dos players com maior poder de mercado ${ }^{12}$. A concentração das reclamações, ilustrada na presente seção, parece corroborar tal assertiva.

\subsection{Temas mais reclamados}

Até aqui, foi possível identificar importantes semelhanças entre as bases de dados de ambos os canais, valendo destacar a aproximação entre a distribuição percentual das reclamações por região geográfica e por operadora. Não obstante, quando examinamos a temática das reclamações registradas em ambos os canais, evidencia-se uma substancial diferença entre as plataformas.

Conforme exposto na Tabela 8 a seguir, um percentual de $40 \%$ das reclamações que ingressam no canal consumidor.gov.br está relacionado ao tema "cobrança/contestação". Em segundo lugar como grupo problema mais reclamado temos "Atendimento/SAC", com 20,84\% das reclamações. E, em terceiro lugar, figura o tema "contrato/oferta" com 16,51\% das reclamações.

12 Nesse sentido, OCKÉ-REIS, Carlos O. Os desafios da ANS frente à concentração dos planos de saúde. Ciência \& Saúde Coletiva, Rio de Janeiro, v. 12, n. 4, p. 1041-1050, 2007. 
Tabela 8 - Reclamações consumidor.gov.br (por tema da reclamação)

\begin{tabular}{|l|r|}
\hline \multicolumn{2}{|c|}{$\begin{array}{c}\text { Consumidor.gov: grupo } \\
\text { problema }\end{array}$} \\
\hline Cobrança/contestação & $41,81 \%$ \\
\hline Atendimento/SAC & $20,84 \%$ \\
\hline Contrato/Oferta & $16,51 \%$ \\
\hline Vício de Qualidade & $15,67 \%$ \\
\hline Informação & $2,88 \%$ \\
\hline Saúde e Segurança & $2,21 \%$ \\
\hline Entrega do Produto & $0,09 \%$ \\
\hline
\end{tabular}

$\mathrm{N}=6.604$

Fonte: Elaboração Própria (consumidor.gov.br)

Ao analisarmos de forma mais detalhada as circunstâncias que estão inseridas dentro do tema mais prevalente na tabela anterior ("Cobrança/contestação"), é possível perceber que os problemas se situam nas cobranças após cancelamento do serviço (22,13\% das reclamações desta categoria) e problemas com a devolução de valores pagos (20,17\%). Trata-se de questões não relacionadas diretamente com a provisão de coberturas médicas, mas sim com assuntos atinentes à cobrança e faturamento.

Tabela 9 - Problemas mais frequentes dentro da categoria "Cobrança/Contestação"

\begin{tabular}{|l|c|}
\hline \multicolumn{2}{|c|}{ Consumidor.gov: problema dado que grupo problema é cobrança/contestação } \\
\hline Cobrança após cancelamento do serviço & $22,13 \%$ \\
\hline Dificuldade/atraso na devolução de valores pagos/reembolso/retenção de valores & $20,17 \%$ \\
\hline Cobrança por valores não previstos/não informados & $12,79 \%$ \\
\hline Reajuste - dúvida ou discordância (exceto idoso) & $9,49 \%$ \\
\hline Outros & $35,42 \%$ \\
\hline
\end{tabular}

$N=2.761$

Fonte: Elaboração Própria (consumidor.gov.br)

O segundo tema mais reclamado no canal consumidor.gov.br contempla diferentes circunstâncias relacionadas ao mau atendimento pelo SAC da operadora, predominando aqueles casos de solicitações não respondidas ou respondidas fora do prazo:

Tabela 10 - Problemas frequentes dentro da categoria "atendimento/SAC"

\begin{tabular}{|l|c|}
\hline \multicolumn{2}{|c|}{ Consumidor.gov: problema dado que grupo problema é atendimento/SAC } \\
\hline SAC - Demanda não resolvida/não respondida/respondida após o prazo & $44,33 \%$ \\
\hline Má qualidade no atendimento presencial ou outros canais (exceto SAC) & $14,97 \%$ \\
\hline SAC - Dificuldade para cancelar o serviço & $14,83 \%$ \\
\hline SAC - Dificuldade de contato/acesso & $8,28 \%$ \\
\hline Outros & $17,59 \%$ \\
\hline
\end{tabular}

$\mathrm{N}=1.376$

Fonte: Elaboração Própria (consumidor.gov.br) 
Dentro do grupo "Contrato/Oferta", as circunstâncias mais frequentes são aquelas relacionadas a irregularidades na publicidade ou no fornecimento do serviço, bem como a alteração/rescisão do contrato sem solicitação ou aviso prévio.

Tabela 11 - Problemas frequentes dentro da categoria "contrato/oferta"

\begin{tabular}{|l|c|}
\hline \multicolumn{2}{|c|}{ Consumidor.gov: problema dado que grupo problema é contrato/oferta } \\
\hline $\begin{array}{l}\text { Oferta não cumprida/serviço não fornecido/venda } \\
\text { enganosa/publicidade enganosa }\end{array}$ & $31,74 \%$ \\
\hline Alteração/rescisão de contrato sem solicitação/aviso prévio & $24,13 \%$ \\
\hline Dificuldade/demora para cancelar o servio & $12,84 \%$ \\
\hline Não entrega do contrato ou documentação relacionada ao serviço & $10,09 \%$ \\
\hline Outros & $21,20 \%$ \\
\hline N $=1.090$
\end{tabular}

Fonte: Elaboração Própria (consumidor.gov.br)

$\mathrm{Na}$ outra ponta, ao analisar o padrão das reclamações registradas perante o canal da ANS, percebe-se que substancial fatia das reclamações (quase 70\%) está relacionada à garantia de coberturas assistenciais (médica ou odontológica).

Tabela 12 - Temas reclamados na ANS

\begin{tabular}{|l|c|c|}
\hline \multicolumn{3}{|c|}{ ANS: principais temas de reclamação } \\
\hline \multicolumn{1}{|c|}{ Tema } & Total & $\%$ \\
\hline Cobertura assistencial & 263.977 & $68,6 \%$ \\
\hline Contratos e Regulamentos & 87.313 & $22,7 \%$ \\
\hline Mensalidades e Reajustes & 30.532 & $7,9 \%$ \\
\hline Outros temas & 3.198 & $0,8 \%$ \\
\hline
\end{tabular}

$\mathrm{N}=385.020$

Fonte: Elaboração própria (ANS Tabnet)

Comparativamente, vislumbra-se que os canais exercem, em alguma medida, papéis complementares entre si: o canal do consumidor.gov.br é mais aderente a reclamações sobre irregularidades na cobrança e no atendimento do SAC, enquanto o canal da ANS tem maior protagonismo na garantia da cobertura a procedimentos médicos e odontológicos (dentro dos prazos estipulados pelas normas regulatórias).

A propósito, é imperioso ressaltar que as reclamações da ANS são processadas no bojo de uma infraestrutura institucional exclusivamente dedicada e baseada em uma intermediação extrajudicial denominada NIP (Notificação de Intermediação Preliminar), pela qual as operadoras são provocadas a dar esclarecimentos sobre os fatos reclamados. A automação viabilizada pela plataforma permite, portanto, a absorção e o processamento de um grande volume de queixas.

Em linhas gerais, a intermediação desempenhada pela agência reguladora em demandas assistenciais funciona da seguinte forma: (i) quando a operadora já realizou ou opta em realizar o procedimento dentro do prazo da NIP - 5 (cinco) dias úteis para demandas envolvendo cobertura assistencial e 10 (dez) dias úteis para os demais casos (não assistenciais), a demanda é inativada e o consumidor recebe uma notificação para confirmação do desfecho apontado; (ii) se a operadora não promove a cobertura no prazo ou insiste em manter uma postura adversarial quanto ao fato reclamado, a reclamação passa a integrar um resíduo de demandas que serão submetidas ao crivo de um analista da agência reguladora que poderá, com base na 
normatização regulatória, finalizar a reclamação por não procedência ou encaminhá-la para a lavratura de auto de infração ${ }^{13}$.

Considerando o grande volume de queixas registradas perante a agência reguladora e a taxa de resolutividade de aproximadamente $90 \%$ (noventa por cento) das demandas ${ }^{14}$, é forçoso reconhecer que a plataforma da ANS exerce um importante papel para a tutela dos direitos dos consumidores.

A dúvida que fica é: se existem canais de resolução extrajudicial de conflitos que funcionam e são complementares entre si - um sob a ótica estritamente consumerista (canal consumidor.gov.br) e outro voltado para questões assistenciais e demais aspectos técnicos da regulação (canal de reclamações da ANS) - por que ferramentas deste tipo não têm sido suficientes para frear a crescente litigância judicial que se observa no setor da saúde suplementar? Este é o ponto da próxima seção.

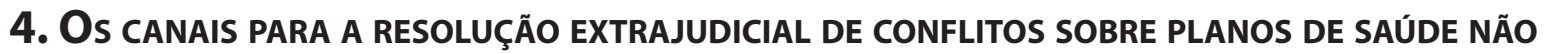 SÃO SUFICIENTES?}

Ao fim e ao cabo, o sucesso de qualquer plataforma de resolução de conflitos depende da sua aptidão para dar um fim ao problema reclamado, seja induzindo a parte reclamada a fornecer aquilo que é postulado na reclamação, seja alcançando uma solução intermediária de comum acordo entre as partes.

O canal de reclamações consumidor.gov.br vem apresentando um volume crescente de registros de reclamações, o que mostra progressiva adesão de consumidores a esta modalidade de resolução de conflitos. O canal da ANS, por seu turno, exerce um relevante papel no processamento de reclamações - especialmente nas queixas sobre coberturas assistenciais, que apresentam desfecho positivo em sua maioria.

Portanto, se ferramentas simples e eficientes estão à disposição dos usuários para a resolução de problemas envolvendo a prestação dos serviços de planos de saúde, porque ainda há forte opção pelos processos judiciais como via de eleição para a obtenção de direitos? Responder esta pergunta não é fácil, mas certamente leva ao enfrentamento das principais causas que sustentam o ciclo de judicialização da saúde suplementar.

É importante salientar que a discussão a ser travada nesta seção não tem a pretensão de enumerar todas as possíveis causas que levam à judicialização da saúde, mas apenas especular quais são os fatores em jogo que incentivam a litigiosidade por meio de ações judiciais em detrimento de outras opções viáveis.

\subsection{Maior notoriedade e acessibilidade do Poder Judiciário}

Um primeiro atributo do Poder Judiciário que se deve levar em conta é a capilarização de sua estrutura por inúmeros municípios. Ademais, na ocorrência de um problema, o reclamante pode ser assessorado inicialmente por profissionais que fazem parte da própria estrutura do Poder Judiciário, a exemplo da Defensoria Pública ou dos núcleos de apoio ao consumidor.

Assim, por desconhecimento do usuário ou pelas circunstâncias relacionadas ao seu primeiro amparo profissional, as plataformas extrajudiciais podem parecer distantes ou pouco efetivas para se pleitear um determinado direito.

13 O procedimento da Notificação de Intermediação Preliminar é descrito pelas subseções que vão do artigo $5^{\circ}$ ao artigo 16 da Resolução Normativa no 388/2015. A Reparação Voluntária e Eficaz (RVE) é disciplinada pelo artigo 20 da mesma resolução. 14 De acordo com o Relatório de Atividades da ANS referente ao ano de 2016, o índice de resolutividade para demandas NIP classificadas como "assistencial" (envolvendo o pleito por coberturas médicas) foi de $88,2 \%$ em 2016. AGÊNCIA NACIONAL DE SAÚDE SUPLEMENTAR - ANS (Brasil). Relatório de atividades 2016. 2017. Disponível em: <http://www.ans.gov.br/images/ stories/A_ANS/Transparencia_ Institucional/Prestacao-de-Contas/Relatorio_de_Atividades/2016_relator io_atividades.pdf $>$. Acesso em: 20 ago. 2018. 
Sob tal perspectiva, é importante que se promova ampla divulgação dos benefícios da utilização de meios extrajudiciais e, na medida do possível, que sejam fortalecidos os acordos de cooperação interinstitucional entre diferentes entidades regionais que recepcionam queixas sobre planos de saúde.

\subsection{Imediatismo das liminares judiciais ou perenidade do direito a ser garantido}

A escolha pela via judicial também pode estar relacionada a condições particulares do próprio pedido, especialmente quando há urgência ou quando se está pleiteando a inclusão do paciente em serviços complexos ou escassos, a exemplo dos centros de tratamento para câncer ou para algumas doenças crônicas.

Inicialmente, discute-se aqui a circunstância que dificilmente é alcançada por meio de plataformas extrajudiciais: o imediatismo para a concessão de pedidos urgentes. Quando o usuário necessita de uma solução imediata, usualmente recorre ao plantão judiciário e, fundamentando-se em laudo de seu médico, requisita que seja dada urgência ao pedido - pleiteando-se, em razão disso, o proferimento de uma liminar judicial.

Se tal imediatismo pode ser plenamente justificado em alguns casos, em outras situações pode ser forçado ou utilizado de forma estratégica para a concessão de uma liminar judicial. Portanto, se numa primeira vista a plataforma extrajudicial poderia ser mais ágil e menos burocrática que um moroso processo judicial, o imediatismo das liminares judiciais quebra esta lógica e promove um grande atrativo para a eleição do judiciário como melhor atalho para o alcance do objetivo pretendido.

A antecipação da tutela judicial em saúde baseia-se em um critério discricionário do juiz no tocante à indisponibilidade do direito tutelado ${ }^{15}$. Não obstante, em cognição sumária, é muito difícil enfrentar questões incidentais relacionadas à cobertura pleiteada, muitas delas complexas, a exemplo de restrições trazidas pelo rol de procedimentos ou prazos de carência ainda não cumpridos. As demandas são apresentadas aos magistrados em um contexto cuja demora na obtenção do direito está associada a infindáveis incertezas quanto ao prognóstico e à irreversibilidade do quadro de saúde do paciente.

Nesta arquitetura de decisão, em que o Judiciário passa a ser o balizador da urgência vinculada aos direitos em saúde, grande parte das liminares se baseiam em laudos médicos apresentados pelos próprios reclamantes $^{16}$. Como consequência, há fortes incentivos para que os juízes não adotem uma posição contrária à documentação médica apresentada ${ }^{17}$.

Esta, a propósito, foi a constatação de uma pesquisa sobre ações judiciais em desfavor de uma operadora de autogestão que foram ajuizadas entre os anos de 1998 a 2009. Do universo de 3.569 ações judiciais, houve a antecipação de tutela em 2.480 delas, o que corresponde a aproximadamente $70 \%$ do total ${ }^{18}$. Em outra pesquisa que examinou o perfil de deferência de antecipação de tutela em diferentes tribunais da região sudeste, observou-se um perfil semelhante: uma taxa de 80,7\% para o Tribunal de Justiça do Rio de Janeiro e de 72,8\% para o Tribunal de Justiça de São Paulo (período entre janeiro de 2003 a setembro de 2004) ${ }^{19}$.

15 FUX, Luiz. Tutela de Urgência e Planos de Saúde. Rio de Janeiro: Espaço Jurídico, 2000.

16 RIBEIRO, Leandro Molhano; HARTMANN, Ivar A. A judicialização do direito à saúde e as mudanças institucionais no Brasil. In: PRADO, Mariana Mota (Org.). O Judiciário e o Estado Regulador brasileiro. São Paulo: FGV Direito SP, 2016.

17 Uma pesquisa foi conduzida a partir da aplicação de uma entrevista direcionada a diferentes juízes e desembargadores do Estado do Maranhão. Foram analisados diferentes aspectos relacionados à percepção dos magistrados sobre as demandas judiciais em saúde. Quando questionados sobre a concessão de liminares, a maior parte dos profissionais se vê em uma posição delicada, cuja recusa pode levar o paciente à morte. Veja-se o trecho da resposta de um dos entrevistados: "Você fica naquele dilema e concede ou não concede uma liminar. Na dúvida, eu pensei: "Quer saber de uma coisa? Melhor conceder porque se esse cara morrer eu não vou ficar com esse peso na consciência”. NEVES, Pilar B. P.; PACHECO, Marcos Antônio B. Saúde pública e Poder Judiciário: percepções de magistrados no estado do Maranhão. Revista de Direito GV, São Paulo, v. 13, n. 3, p. 749-768, set./dez. 2017.

18 OLIVEIRA, José A. D.; FORTES, Paulo A.C. De que reclamam afinal? Estudo de ações judiciais contra uma operadora de plano de saúde. Revista de Direito Sanitário, São Paulo, v. 13, n. 3, p. 33-58, nov/fev. 2013.

19 ALVES, Daniele Conte; BAHIA, Ligia; BARROSO, André Feijó. O papel da Justiça nos planos e seguros de saúde no Brasil. Cadernos de Saúde Pública, Rio de Janeiro, v. 25, n. 2, p. 279-290, fev. 2009. 
Para além da rapidez quanto à obtenção do direito, as decisões judiciais também garantem maior perenidade ao objeto pleiteado, especialmente nos casos em que a cobertura é prolongada e o consumidor necessita ser incluído em algum tipo de serviço que demande o contínuo fornecimento de medicamentos ou terapias.

A propósito, as solicitações de medicamentos são um excelente exemplo nesse sentido: se o consumidor ingressa com uma reclamação em um canal extrajudicial requisitando o custeio de um determinado medicamento, a resolução do conflito será feita pontualmente e o chamado será encerrado de forma bem-sucedida assim que for comprovada a entrega do fármaco. Nada garante, entretanto, que a operadora viole a continuidade do tratamento algumas semanas depois, obrigando que o usuário ingresse com uma nova reclamação.

Considerando o potencial risco de descumprimento futuro de obrigações que possuem natureza longa e contínua, a decisão judicial parece apresentar maior coercitividade e, assim, transmite ao consumidor um maior grau de confiança quanto à inibição do prestador do serviço no tocante a um eventual cancelamento no fornecimento da terapia ou do medicamento (ao arrepio da ordem do magistrado).

Para alinhar incentivos, é necessário corrigir tal assimetria atacando as duas frentes: criando atrativos para o uso de mecanismos extrajudiciais e restringindo a banalização de alguns pedidos deferidos por liminar judicial.

O reforço da via extrajudicial pode ser feito criando plantões e outras formas cada vez mais rápidas para a resolução do conflito (quando certas condições estiverem presentes). Por seu turno, o Poder Judiciário pode ampliar a utilização de pareceres fornecidos por especialistas para subsidiar os magistrados no que concerne à procedência daquilo que está sendo requisitado liminarmente - criando-se um parâmetro mais criterioso nesse sentido.

\subsection{O conteúdo das decisões pode gerar incentivos para mais judicialização}

Quando uma reclamação é efetuada, o caso concreto que lhe deu causa pode ser examinado sob diferentes perspectivas. Em uma primeira perspectiva, o intérprete pode levar em conta algumas limitações trazidas por normas técnicas e, assim, julgar aquela reclamação improcedente. Em sentido diverso, a mesma situação pode ser inserida dentro de um contexto mais garantista e favorável ao consumidor.

Portanto, se o canal extrajudicial adota alguma norma regulatória que é mais restritiva ao consumidor e os processos judiciais garantem uma maior amplitude de direitos, cria-se um desalinhamento de tratamentos que pode gerar frustrações e induzir o usuário para a escolha da via judicial como primeira opção.

Neste contexto, embora a maioria das decisões judiciais favoráveis ao consumidor sejam mantidas pelos tribunais ${ }^{20}$, tal constatação, isoladamente considerada, não permite inferir que o Poder Judiciário considerou todo o acervo de normas regulatórias para dirimir o conflito.

Basta constatar que, muito recentemente, em abril de 2018, a $1^{\text {a }}$ Seção do Superior Tribunal de Justiça concluiu o julgamento do Recurso Especial no 1.657 .156 / RJ ${ }^{21}$, estabelecendo-se critérios mínimos para

20 Diferentes pesquisas apontam para um expressivo percentual de manutenção daquelas decisões judiciais que são favoráveis a consumidores de planos de saúde quando questionadas perante os tribunais locais. Como exemplo, podemos citar as seguintes taxas: 88,24\% de decisões favoráveis no Tribunal de Justiça de SP em 2009 e 2010. SCHEFFER, Mário César. Coberturas assistenciais negadas pelos planos e seguros de saúde em ações julgadas pelo Tribunal de Justiça do Estado de São Paulo. Revista de Direito Sanitário, São Paulo, v. 14, n. 1, p. 122-132, mar./jun. 2013. 92,5\% dos pleitos atendidos para casos julgados pelo Tribunal de Justiça de SP envolvendo planos coletivos. ROBBA, Rafael. Judicialização dos planos e seguros de saúde coletivos no Tribunal de Justiça de São Paulo. Dissertação (Mestrado) - Faculdade de Medicina da USP, São Paulo, 2017. 82,1\% de decisões favoráveis ao consumidor questionadas perante o Superior Tribunal de Justiça entre os anos de 1990 a 2008. TRETTEL, Daniela Batalha. Planos de saúde na Justiça: o direito à saúde está sendo efetivado? Dissertação (Mestrado) - Faculdade de Direito da USP, São Paulo, 2009.

21 SUPERIOR TRIBUNAL DE JUSTIÇA. Recurso Especialnº 1.657.156 / RJ, 2018. Relator Ministro Benedito Gonçalves, $1^{a}$ Seção do STJ, Julgado em 24/04/2018 (DJe 04/05/2018). Disponível em: <https://ww2.stj.jus.br/processo/revista/inteiroteor/?num_ 
que o Poder Judiciário determine o fornecimento de remédios fora da lista do SUS. Foi decidido que devem estar presentes, cumulativamente, os seguintes requisitos: laudo do médico do paciente comprovando que o medicamento é imprescindível e que os medicamentos fornecidos pelo SUS são ineficazes para o tratamento pretendido; demonstração da incapacidade financeira do paciente de arcar com o custo do medicamento prescrito; e existência de registro do medicamento na Agência Nacional de Vigilância Sanitária (ANVISA).

Embora a jurisprudência esteja voltada aos casos aplicáveis ao sistema público de saúde, há registros de decisões judiciais semelhantes na esfera da saúde suplementar ${ }^{22}$. A situação é emblemática para ilustrar algumas das exceções criadas pelo ativismo judicial nas demandas envolvendo assistência à saúde. Afinal, há fontes no ordenamento jurídico apontando para a proibição da livre comercialização destes produtos ${ }^{23}$. Portanto, de um lado, exige-se que os medicamentos a serem vendidos no Brasil sejam amparados pelo registro da autoridade sanitária e, na outra extremidade, sentenças judiciais obrigam que tal substância irregular (sob a perspectiva sanitária federal) seja adquirida para o consumo.

Para além da normatização da ANVISA, as decisões judiciais sobre planos de saúde também podem ignorar ou simplesmente não contemplar as condições regulatórias positivadas pela ANS.

Sobre a questão, é imperioso destacar que grande parte do conteúdo normativo que incide perante as relações contratuais envolvendo planos de saúde está situada no nível infralegal. A Lei nº 9656/98 (lei dos planos de saúde) tão somente delimita as regras gerais, enquanto a Lei no 9961/2000 (lei de criação da ANS) atribui uma série de competências que serão exercidas pela agência reguladora mediante a expedição de atos administrativos e resoluções normativas.

Desta forma, quando alguma queixa é apresentada ao Poder Judiciário e o magistrado não leva em consideração a disciplina trazida pelas resoluções infralegais, a interpretação judicial acaba se fazendo valer como norma regulatória, eis que extrai alguma solução do ordenamento jurídico para disciplinar diferentes conflitos sobre planos de saúde.

Neste cenário, tendo o Código de Defesa do Consumidor (CDC) um conteúdo mais flexível e principiológico, grande parte dos conflitos judiciais são regulados à luz da normatização consumerista. É o que se infere dos resultados da pesquisa de Rafael Robba, que examinou o conteúdo das decisões do TJSP em conflitos envolvendo planos de saúde coletivos em 2013 e 2014: a fundamentação de 56,7\% das decisões ampara-se no CDC, enquanto que aquelas que citam normas da ANS totalizam aproximadamente $2 \%$ (dois por cento) ${ }^{24}$.

Se, por um lado, a legislação consumerista parece ser mais protetiva para a tutela do caso concreto, seu uso pode colidir frontalmente com a lógica de algumas normas técnicas criadas pela agência reguladora. No longo prazo, isso fragiliza a previsibilidade e a segurança jurídica sobre quais regras devem ser levadas a sério pelos players do setor.

registro $=201700256297 \& d t \_$publicacao $=04 / 05 / 2018>$. Acesso em: 02 set. 2018.

22 A notícia a seguir ilustra que várias decisões proferidas pelos tribunais chegam ao STJ versando sobre a determinação judicial para a cobertura de medicamentos não registrados pela ANVISA. O GLOBO. STJ suspende ações que pedem fornecimento de medicamentos importados por planos de saúde. Disponível em: https://oglobo.globo.com/economia/defesa-do-consumidor/stjsuspende-acoes-que-pedem-fornecimento-de-medicamentos-importados-por-planos-de-saude-22515451. Acesso em: 21 ago. 2018. 23 "Art. 273 - Falsificar, corromper, adulterar ou alterar produto destinado a fins terapêuticos ou medicinais:

Pena - reclusão, de 10 (dez) a 15 (quinze) anos, e multa.

$\int 1^{\circ}$ - Nas mesmas penas incorre quem importa, vende, expõe à venda, tem em depósito para vender ou, de qualquer forma, distribui ou entrega a consumo o produto falsificado, corrompido, adulterado ou alterado.

$[\cdots]$

$\int 1^{\circ}$-B - Está sujeito às penas deste artigo quem pratica as ações previstas no $\int 1^{\circ} \mathrm{em}$ relação a produtos em qualquer das seguintes condições:

$[\ldots]$

I - sem registro, quando exigível, no órgão de vigilância sanitária competente".

24 Valor atribuído à soma de todas as citações contabilizadas sobre: Resolução Normativa no 279/2011 (1\%); resoluções diversas sobre o rol de procedimentos (0,9\%); e Resolução Normativa 195/2009 (0,3\%). ROBBA, Rafael. Judicialização dos planos e seguros de saúde coletivos no Tribunal de Justiça de São Paulo. Dissertação (Mestrado) - Faculdade de Medicina da USP, São Paulo, 2017. p. 51. 
Toma-se, por exemplo, as normas regulatórias que disciplinam as diretrizes de utilização para certas coberturas previstas pelo rol de procedimentos da ANS. A idealização destas diretrizes é que a cobertura a um determinado procedimento seja elegível quando preenchidas certas condições preconizadas pela melhor literatura disponível (medicina baseada em evidências). Em outras palavras, a norma regulatória permite que um mesmo procedimento seja autorizado para uma indicação médica e negado para outra. A lógica de escassez que serve como pano de fundo para a norma regulatória perde totalmente a sustentação quando confrontada com a Súmula no 102 do TJSP, abaixo transcrita, que atribui a "palavra final" exclusivamente ao médico solicitante: "Sumula 102. Havendo expressa indicação médica, é abusiva a negativa de cobertura de custeio de tratamento sob o argumento da sua natureza experimental ou por não estar previsto no rol de procedimentos da ANS".

Outro exemplo de afastamento da normatização regulatória são as declarações de ilegalidade das cláusulas contratuais redigidas como base na Resolução CONSU n ${ }^{\circ} 13 / 98$, que disciplina os limites de cobertura para urgências e emergências em planos de saúde. Embora a legitimidade da norma tenha sido reconhecida pela justiça federal, ocasião em que a resolução poderia ter sido afastada do ordenamento, a regra é sistematicamente afastada pela jurisprudência de alguns tribunais estaduais ${ }^{25}$.

Não se pretende aqui esgotar todos os casos em que o Poder Judiciário, voluntariamente ou por desconhecimento, decide em sentido contrário ao disciplinado pelas normas regulatórias ${ }^{26}$. Tampouco se advoga pela prevalência das normas regulatórias a qualquer custo. O propósito é tentar explicar como este conflito de interpretações pode gerar assimetrias de tratamento e, assim, dificultar o estabelecimento de parâmetros claros para o tratamento de certos litígios.

A simplificação regulatória e a redução da assimetria de informações certamente estão entre as soluções para facilitar a compreensão da normatização aplicável. De acordo estudo desenvolvido por Mario Scheffer sobre o perfil da judicialização dos planos de saúde perante o TJSP, a diversidade de justificativas das empresas de planos de saúde para a restrição da assistência médica ${ }^{27}$ indica a complexidade da regulação e, ao mesmo tempo, aponta para possibilidades concretas de aperfeiçoamento da legislação.

De acordo com a literatura econômica ${ }^{28}$, agentes racionais têm comportamento estratégico. Quando isso ocorre, podemos dizer que os agentes se deparam com um jogo, e, em tais situações, a Teoria dos Jogos analisa e ajuda a prever as estratégias racionais desses indivíduos ${ }^{29}$.

25 Trata-se da conclusão de pesquisa empírica sobre o tratamento dado pelos Tribunais do Rio de Janeiro, São Paulo e Minas Gerais à Resolução CONSU no $13 / 98$ (que disciplina a cobertura para os casos de urgência e emergência). Observou-se que a norma regulatória é declarada ilegal na quase totalidade dos julgados examinados (apenas uma pequena parcela de acórdãos proferidos pelo TJ-SP foi em sentido contrário). Conforme destacado pelo autor, a mesma resolução já havia sido questionada em âmbito federal no bojo da Ação Civil Pública n. 2009.61.00.002894-4, julgada na 6 ${ }^{a}$ Vara Federal da subseção judiciária de São Paulo, ocasião em que foi considerada dentro dos limites da legalidade e de discricionariedade técnica do Poder Executivo. Portanto, embora a Justiça Federal tenha reconhecido a legitimidade da norma, os tribunais estaduais declaram nulas aquelas cláusulas que instrumentalizam o seu conteúdo. Como resultado, é produzido um controle judicial “indireto”, oblíquo, no qual a norma regulatória, embora não expurgada do ordenamento, é sistematicamente desconsiderada em inúmeras decisões isoladas de cada Justiça Estadual. RAMALHO, Bruno Araujo. A Interface institucional entre a ANS e o Poder Judiciário: análise de acórdãos sobre a cobertura de emergências médicas em planos de saúde. Revista De Direito Sanitário, São Paulo, v. 17, n. 1, p. 122-144, 2016.

26 Sobre a questão, a pesquisa de Rafael Robba traz uma valiosa sistematização das principais teses conflitantes (entre o posicionamento do TJSP e as normas da ANS). ROBBA, Judicialização dos planos e seguros de saúde coletivos no Tribunal de Justiça de São Paulo. Dissertação (Mestrado) - Faculdade de Medicina da USP, São Paulo, 2017. Igualmente importante para ilustrar os conflitos entre o Poder Judiciário e as normas da ANS, vale destacar: TRETTEL, Daniela Batalha; KOZAN, Juliana Ferreira; SCHEFFER, Mário César. Judicialização em planos de saúde coletivos: os efeitos da opção regulatória da Agência Nacional de Saúde Suplementar nos conflitos entre consumidores e operadoras. Revista De Direito Sanitário, São Paulo, v. 19, n. 1, p. 166-187, 2018.

27 Segundo a pesquisa, as justificativas mais utilizadas foram: (i) não previsão do procedimento no rol da ANS; (ii) ausência de previsão contratual para um determinado procedimento; (iii) não cumprimento de prazo de carência; (iv) hospital procurado pelo beneficiário não faz parte da rede contratada; (v) não obrigatoriedade do plano de saúde cobrir o custeio de medicamentos de uso domiciliar e oral. SCHEFFER, Mário, Coberturas assistenciais negadas pelos planos e seguros de saúde em ações julgadas pelo Tribunal de Justiça do Estado de São Paulo. Revista de Direito Sanitário, São Paulo, v. 14, n. 1, p. 128-129, mar./jun. 2013.

28 MAS-COLELL, Andreu et al. Microeconomic theory. New York, EUA: Oxford University Press, 1995.

29 GIBBONS, Robert. Game theory for applied economists. Princeton, EUA: Princeton University Press, 1992. 
Baseando-se na citada teoria, é imperioso reconhecer que os comportamentos não são ditados, mas sim influenciados pela norma legal, visto que em certas circunstâncias pode ser racional ir contra ela ${ }^{30}$. Adicionalmente, a lei e a jurisprudência podem permitir mais de um tipo de comportamento, de tal sorte que a escolha de qual será seguido pode depender da interação entre indivíduos.

Ao saber que a probabilidade de ganhar uma demanda no judiciário é alta, os incentivos estão claros pela perspectiva do consumidor. Assim, as possíveis ações de um consumidor para litigar podem ser representadas na árvore de decisão a seguir:

Gráfico 4 - Árvore de Decisão

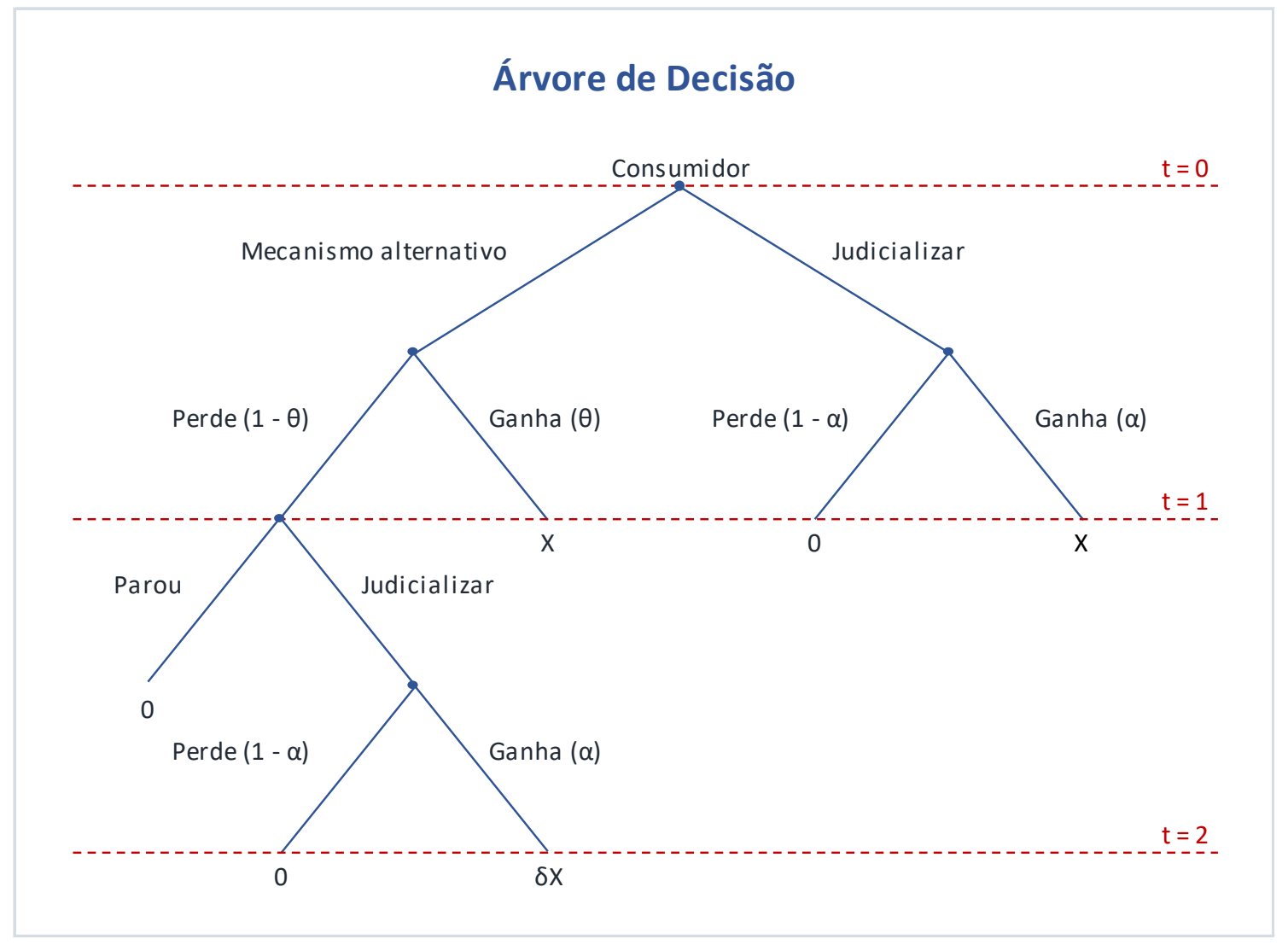

Fonte: Elaboração Própria

Vamos admitir que o consumidor tenha alguma demanda a ser resolvida com sua operadora e, inicialmente, possua duas opções: judicializar a questão ou tentar resolvê-la através de algum mecanismo alternativo, a exemplo do site consumidor.gov ou canal da ANS. Caso o consumidor resolva judicializar, existem dois possíveis resultados: ganhar a causa ou perder. Vamos admitir que, independentemente do resultado, o jogo termina.

Em um segundo eixo, o consumidor deixaria de judicializar e tentaria resolver através de algum mecanismo alternativo de resolução de conflitos. Novamente, existem dois possíveis resultados: ganhar ou perder a demanda. No entanto, desta vez, caso o consumidor perca, ele ainda possui a opção de judicializar - o que mais uma vez, leva a dois resultados possíveis, quais sejam, perder ou ganhar a ação (terminando-se aí o jogo).

Considerando ambos os feixes de escolha, a cronologia do jogo ocorre da seguinte forma: (i) em $t=0 \mathrm{o}$ consumidor decide se judicializa ou tenta algum mecanismo alternativo; (ii) em $t=1$, o consumidor descobre se ganhou ou perdeu no processo judicial ou no extrajudicial; (iii) caso o consumidor tenha tentado a via extrajudicial e tenha perdido, ele pode ainda judicializar e o resultado da judicialização será realizado em $t=2$.

30 PINHEIRO, Armando Castelar; SADDI, Jairo. Direito, economia e mercados. São Paulo: Campus, 2005. 
Há que se levar em consideração o desconto intertemporal dos consumidores. Afinal, a opção de resolução através da via extrajudicial só vale a pena caso a probabilidade de sucesso se mostre superior à probabilidade de sucesso através da via judicial. Suponha que o consumidor considere que a probabilidade de ganhar a disputa através da via extrajudicial seja de $\theta$ e de perder (1- $\theta)$. Suponha também que a probabilidade de ganhar a disputa através da via judicial seja de $\alpha$ e de perder $(1-\alpha)$. Além disso, vamos admitir que, quando o consumidor ganha a disputa, independentemente da via escolhida, ele recebe $\mathrm{X}$ de payoff. Caso o consumidor perca, ele recebe 0 de payoff. Além disso, tome $\delta$ como a taxa de desconto intertemporal. Logo,

Ganho esperado da judicialização: $(1-\alpha) 0+\alpha \mathrm{X}$

Ganho esperado da via extrajudicial: $(1-\theta)[0+(1-\alpha) 0+\alpha \delta \mathrm{X}]+\theta \mathrm{X}$.

Destarte, para que o consumidor escolha inicialmente a via alternativa ao invés da via judicial, o ganho esperado de entrar com um processo judicial precisa ser menor do que o ganho esperado de tentar um mecanismo alternativo. Ou seja,

$$
\begin{gathered}
(1-\theta)[0+(1-\alpha) 0+\alpha \delta \mathrm{X}]+\theta \mathrm{X}>(1-\alpha) 0+\alpha \mathrm{X} \\
(1-\theta) \alpha \delta \mathrm{X}+\theta \mathrm{X}>\alpha \mathrm{X} \\
(1-\theta) \alpha \delta+\theta>\alpha \\
\alpha \delta+\theta(1-\alpha \delta)>\alpha \\
\theta(1-\alpha \delta)>\alpha(1-\alpha) \\
\frac{\theta}{\alpha}>\frac{(1-\alpha)}{(1-\alpha \delta)} \\
\text { Como }(1-\alpha)>(1-\alpha \delta) \text { então, } \frac{(1-\alpha)}{(1-\alpha \delta)}>1 \cdot \frac{(1-\alpha)}{(1-\alpha \delta)}>1 . \operatorname{Logo}, \frac{\theta}{\alpha}>1 . \frac{\theta}{\alpha}>1 .
\end{gathered}
$$

Portanto, se mantidas iguais as condições de tempo por jogada ${ }^{31}$, para que o consumidor queira resolver sua disputa através de mecanismo alternativo ao invés da via judicial, é imperioso que a probabilidade de ganhar no primeiro caso não seja menor que a probabilidade de ganho no segundo caso.

\subsection{As principais estratégias para reduzir a "judicialização da saúde" priorizam o Poder Judiciário como o centro da tomada de decisão}

Embora se especule que a judicialização possa desencadear inovações institucionais e fomentar a implementação de novos direitos sociais ${ }^{32}$, a escalada dos custos da judicialização é preocupante e fala por si.

Neste contexto, são valiosas as iniciativas do Conselho Nacional de Justiça (CNJ) no sentido de aprimorar a qualidade técnica das decisões judiciais por meio de ferramentas como o NAT-JUS ${ }^{33}$ e demais formas de coleta de subsídios técnicos para garantir maior racionalidade às decisões judiciais. Afinal, a maior tecnicidade na avaliação dos pleitos judiciais pode criar, em certa medida, um desincentivo para o ajuizamento de ações judiciais flagrantemente improcedentes ou em desacordo com a regulação aplicável.

\footnotetext{
31 Sobre a variável "tempo", vale destacar que a opção por "judicializar" pode ter uma diminuta duração nos casos em que o magistrado concede medidas liminares para garantir o objeto pleiteado pelo autor, nos termos já abordados na seção 4.2 - tornandoa ainda mais vantajosa como primeira opção a ser escolhida na dinâmica ilustrada pelo jogo.

32 Há poucos estudos empíricos dedicados a demonstrar qual é a relação de causalidade entre a litigância envolvendo o direito à saúde e: (1) mudanças políticas no setor de saúde; (2) mudanças institucionais no setor de saúde; e (3) mudanças institucionais indiretas (fora do setor de saúde, a exemplo de mudanças na arquitetura institucional do Poder Judiciário). PRADO, Mariana M. The Debatable Role of Courts in Brazil's Health Care System: Does Litigation Harm or Help? Journal of Law, Medicine \& Etbics, v. 41, n. 1, p. 124-137, mar./jun. 2013.

33 Trata-se de plataforma lançada em novembro de 2017 e que tem o intuito de fornecer insumos para subsidiar as decisões de magistrados nas ações judiciais envolvendo saúde. A notícia sobre o lançamento da plataforma encontra-se disponível em: <http:// www.cnj.jus.br/noticias/cnj/85802-ministra-lanca-plataforma-para-subsidiar-decisoes-com-evidencia-medica>. Acesso em: 25 ago. 2018.
} 
Não obstante, conforme observa Leandro Molhano e Ivar Hartmann ${ }^{34}$, o objetivo oficialmente declarado quando da criação dos Núcleos de Apoio Técnico (NATs) não foi reduzir o número de ações judiciais relacionadas à saúde, mas tão somente preencher espaços técnicos não dominados pelos magistrados. Permanece, portanto, a hegemonia da tomada de decisão alocada no Poder Judiciário, o que se insere dentro de um contexto em que judicialização vê-se obrigada a criar ferramentas para lidar com sua própria onipresença.

E, mesmo sob a adoção deste tipo de arranjo decisório, permanecem dilemas de confiança sobre a credibilidade daqueles técnicos que seriam responsáveis pela orientação técnica das decisões judiciais em planos de saúde ${ }^{35}$ e problemas relacionados ao grau de aceitação dos magistrados em submeter suas decisões ao arrazoado trazido pelos membros do núcleo técnico. Sobre esta última questão, vale destacar a tese de doutorado que investigou a incorporação de pareceres técnicos nas decisões judiciais sobre assistência pública à saúde no Estado do Rio de Janeiro. De acordo com o estudo, foram identificados diferentes casos em que a contribuição do NAT não foi suficiente para o convencimento do magistrado em oposição à documentação médica apresentada pelo autor da ação. Assim concluiu a autora do trabalho:

O resultado do estudo apontou uma ausência de utilização dos Pareceres técnico-científicos no discurso judicial. Nos processos judiciais em que foram apresentadas sugestões de alternativas terapêuticas disponíveis no SUS, esta premissa não foi considerada devidamente no processo decisório, comprometendo a validade discursiva da argumentação e decisão judiciais. Certas questões, como custo-efetividade, eficácia, efetividade e os limites aceitáveis das restrições médico-sanitárias em relação ao acesso à terapêutica no SUS não são aprofundadas e apontam uma relativa incompreensão da linguagem médico-sanitária.

As decisões judiciais que envolvem o direito à assistência terapêutica continuam adotando a presunção de que a prescrição médica individual é a indicação mais segura da imprescindibilidade da terapêutica pleiteada, e se não comprovada por meio de provas materiais contrárias, pelos réus-gestores a veracidade desta prescrição e/ou do diagnóstico, os magistrados entendem que as prescrições individuais são plenamente válidas para obrigar o ente público a fornecer a terapêutica reclamada ${ }^{36}$.

Nesta linha de ideias, o incremento de racionalidade e de tecnicidade nas decisões judiciais sobre saúde é um passo importante, mas insuficiente. Para que exista, realmente, um menor protagonismo da via judicial como arena de resolução de litígios em planos de saúde, é imperioso alinhar incentivos entre canais extrajudiciais e judiciais, de maneira que os primeiros sejam elegíveis como a escolha mais eficiente (pela rapidez, praticidade, e outros atributos) e, ao mesmo tempo, a operadora de planos de saúde sinta-se impelida a resolver o litígio antes da sua evolução para aquele que deve ser interpretado como o nível mais crítico de litigância: a esfera judicial.

Assim, considerando a demanda judicial como o reflexo de um problema não resolvido, o desenho institucional deve ser pensado para que se fortaleçam outras vias de solução de conflitos, de forma a torná-las mais atrativas, especialmente no que tange à praticidade e ao custo subjacente à resolução da queixa. Transferir este protagonismo para outras esferas controladas pelo poder público não é uma tarefa fácil, já que o uso do Poder Judiciário como instrumento de consagração de direitos decorre, em alguma medida, da descrença da população com relação ao funcionamento das instituições do Poder Executivo e quanto à legitimidade dos legisladores que formulam as políticas públicas ${ }^{37}$.

34 RIBEIRO, Leandro Molhano; HARTMANN, Ivar A. A judicialização do direito à saúde e as mudanças institucionais no Brasil. In: PRADO, Mariana Mota (Org.) O Judiciário e o Estado Regulador brasileiro. São Paulo: FGV Direito SP, 2016. p. $246-247$.

35 Nesse sentido, vale destacar a manifestação da Proteste questionando a possível ausência de imparcialidade na atuação do núcleo de mediação do TJSP para casos envolvendo planos de saúde. Segundo a entidade, o formato de escolha pode levar a uma solução quase imposta por uma das partes - no caso os planos de saúde. Assim, preconizam que a mediação seja conduzida por alguém neutro, ou então por uma câmara de mediação/conciliação em plantão permanente, e integrada por: um técnico neutro; um representante de uma das partes (no caso os planos de saúde); um representante do consumidor (órgão público ou entidade nãogovernamental de proteção e defesa do consumidor). A notícia sobre o manifesto está disponível em: <https://www.proteste.org. br/ saude-e-bem-estar/plano-de-saude/noticia/planos-de-saude-nucleo-de-mediacao-e-parcial>. Acesso em: 28 ago. 2018.

36 SILVA, Miriam Ventura da. O processo decisório judicial e a assessoria técnica: a argumentação jurídica e médico-sanitária na garantia do direito à assistência terapêutica no Sistema Único de Saúde. Tese (Doutorado) - Escola Nacional de Saúde Pública Sergio Arouca, Rio de Janeiro, 2012. p. 172-173.

37 Nesse sentido, vale destacar a compreensão trazida pelo jurista Luís Roberto Barroso sobre o papel institucional do Supremo 
Em um primeiro nível, é fundamental que os sistemas de atendimento das próprias operadoras sejam reforçados para que o consumidor deposite confiança no serviço e sinta-se apto para resolver o problema dentro da esfera de ingerência da própria empresa responsável pelo serviço. Para tanto, o protagonismo do canal consumidor.gov.br em forçar a melhoria nos sistemas de atendimento ao consumidor (SAC) das empresas pode ser bastante útil para induzir melhorias. As normas da ANS também sinalizam uma abordagem semelhante: em 2013 publicou-se uma resolução estabelecendo critérios mínimos para a infraestrutura das ouvidorias de operadoras de planos de saúde e, em 2016, outra norma disciplinou uma série de requisitos para o fornecimento de informações aos consumidores a respeito de coberturas assistenciais ${ }^{38}$.

Em um segundo nível, devem haver incentivos (especialmente de tempo e custo) para o uso de alternativas de autocomposição extrajudicial, de maneira a reforçar o protagonismo da agência reguladora e, em níveis locais, privilegiar técnicas de mediação ${ }^{39}$ fazendo-se uso de câmaras regionais de mediação ${ }^{40}$.

Em um terceiro nível, é imperioso fortalecer o diálogo entre as partes que lidam com as interpretações relacionadas ao conteúdo da regulação, contribuindo-se para uma interface mais harmoniosa entre a agência reguladora e o Poder Judiciário. A partir deste diálogo, podem ser idealizadas ferramentas para minimizar a assimetria de informação e promover ajustes para simplificar a regulação aplicável aos casos notadamente mais problemáticos.

Por fim, as instituições que atuam perante o Poder Judiciário devem privilegiar uma atuação mais ampla e preventiva, utilizando-se de acordos coletivos e métodos consensuais para pactuar a correção de casos mais recorrentes e, assim, minimizar a entrada de ações judiciais isoladas ${ }^{41}$.

Ante todo o exposto, conclui-se que os canais de resolução extrajudicial abordados pelo presente estudo possuem um importante papel institucional, mas são insuficientes para, isoladamente, frear o crescimento da judicialização da saúde. Para tanto, é necessário levar a sério as seguintes iniciativas: (i) maior tecnicidade das decisões judiciais, especialmente aquelas que envolvem a concessão de liminares; (ii) arquitetura institucional que privilegie o uso de plataformas de resolução extrajudicial de conflitos em detrimento de ações judiciais; e (iii) uso de ferramentas coletivas e proativas por parte das instituições reguladoras e dos órgãos que representam consumidores perante o Poder Judiciário.

Tribunal Federal. Para o autor, a corte suprema tem atuado como uma "vanguarda iluminista" quando lida com questões difíceis envolvendo demandas sociais. Neste diapasão, argumenta-se que a corte constitucional acaba empurrando a ordem jurídica para a consagração de direitos e conquistas que, embora relevantes, simplesmente não são contempladas por aqueles que formulam as leis. BARROSO, Luis Roberto. A razão sem voto: o Supremo Tribunal Federal e o governo da maioria. Revista Brasileira de Políticas Públicas, Brasília, v. 5, Número Especial. 2015.

38 Aqui, faz-se referência a duas normas especificamente: (i) a Resolução Normativa no 323, publicada em 3 de abril de 2013, que determina a instituição de unidade organizacional específica de ouvidoria pelas operadoras de planos privados de assistência à saúde; $\mathrm{e}$ (ii) a Resolução Normativa $n^{\circ}$ 395, publicada em 14 de janeiro de 2016, que disciplina as regras a serem observadas pelas Operadoras de Planos Privados de Assistência à Saúde nas solicitações de procedimentos e/ou serviços de cobertura assistencial apresentados pelos beneficiários. Ambas estão disponíveis em: <http://www.ans.gov.br/legislacao/busca-de-legislacao>. Acesso em: 20 ago. 2018.

39 Em linhas gerais, a principal diferença entre "arbitragem" e "mediação" reside na forma como se dá a resolução do conflito. $\mathrm{Na}$ arbitragem, o árbitro é um especialista que examina os fatos que orbitam sobre o litígio e decide a lide. Na mediação, há um intermediário entre os litigantes (mediador) que apenas busca facilitar a negociação e convencê-los a alcançar, juntos, um consenso que seja apto a solucionar a controvérsia. FREGAPANI, Guilherme Silva Barbosa. Formas alternativas de solução de conflitos e a lei dos juizados especiais cíveis. Revista de Informação Legislativa, v. 34, n. 133, p. 99-107, jan./mar. 1997. p. 101.

40 No âmbito da saúde pública já existem algumas iniciativas nesse sentido, tais como: (i) a câmara de conciliação de litígios ligados à saúde, do Estado do Rio de Janeiro, e (ii) o "SUS mediado" (mecanismo extrajudicial do Estado do Rio Grande do Norte formalizado entre secretaria do estado de saude, defensoria publica e procuradorias estadual e federal). RIBEIRO, Leandro Molhano; HARTMANN, Ivar A. A judicialização do direito à saúde e as mudanças institucionais no Brasil. In: PRADO, Mariana Mota (Org.). O Judiciário e o Estado Regulador brasileiro. São Paulo: FGV Direito SP, 2016. p. 240.

41 Conforme descreve Felipe Dutra Asensi, há uma distinção entre "judicialização" e "juridicização". Na primeira, o Poder Judiciário é chamado a decidir no sentido da resolução definitiva de um determinado conflito. Na segunda hipótese, predomina a ideia de consenso pelo diálogo, ou seja, a ênfase num processo de negociação, pactuação e concessão recíproca entre os diversos atores cujo resultado é construído consensualmente. Trata-se de uma valiosa forma de atuação das instituições jurídicas que vai além da mera judicialização. ASENSI, Felipe Dutra. Judicialização ou juridicização? As instituições jurídicas e suas estratégias na saúde. Physis - Revista de Saúde Coletiva, Rio de Janeiro, v. 20, n. 1, p. 33-55, 2010. p. 48-49. 


\section{Considerações Finais}

Os números crescentes da judicialização no setor de saúde suplementar revelam um atrito problemático entre consumidores e operadoras de planos de saúde e despertam uma série de preocupações sobre a forma como devem ser desenhadas as políticas públicas para que se tenha um mercado com menores níveis de litigância judicial.

O sucesso de qualquer plataforma para a resolução de conflitos depende da sua aptidão para dar fim ao problema, seja induzindo a parte reclamada a fornecer aquilo que é postulado na reclamação, seja alcançando uma solução intermediária de comum acordo entre as partes. Assim, considerando os custos inerentes à judicialização da saúde, é fundamental conhecer as particularidades existentes nas atuais plataformas de resolução extrajudicial de conflitos.

O presente artigo comparou diferentes elementos presentes nas reclamações registradas no canal consumidor.gov.br e no canal da ANS, concluindo-se que ambos exercem um importante papel social e, em alguma medida, desempenham papéis complementares entre si: o canal do consumidor recebe maior volume relacionado a cobranças indevidas e irregularidades com SAC, enquanto parcela substancial das reclamações tratadas pelo canal da ANS versa sobre a garantia de coberturas assistenciais.

De acordo com o conteúdo pesquisado, foi possível constatar padrões bem semelhantes, a exemplo do maior percentual de reclamações na região sudeste e da forte concentração das queixas atribuídas a um número bem reduzido de operadoras.

Embora tais plataformas sejam instrumentos simples e gratuitos para a resolução de problemas envolvendo os serviços de planos de saúde, o uso isolado destas ferramentas não é suficiente para eliminar a excessiva utilização do Poder Judiciário como palanque adversarial. Isso se deve a diferentes hipóteses (a serem confirmadas por estudos futuros), dentre as quais podemos destacar: (i) a maior notoriedade e acessibilidade do Poder Judiciário; (ii) o imediatismo garantido pelas liminares judiciais; (iii) o conteúdo favorável das decisões, o que leva a mais judicialização; e (iv) a manutenção do Poder Judiciário como centro da tomada de decisão.

Portanto, para além das políticas públicas que estabeleçam ferramentas de apoio técnico para conferir maior consistência às decisões judiciais, é fundamental que seja adotada uma arquitetura institucional que privilegie métodos consensuais e incentive o uso de plataformas de resolução extrajudicial de conflitos. Paralelamente, deve haver uma interface harmoniosa entre os entendimentos do Poder Judiciário e aquele conteúdo disciplinado pelas normas da agência reguladora do setor.

\section{REFERÊNCIAS}

AGÊNCIA NACIONAL DE SAÚDE SUPLEMENTAR - ANS (Brasil). Caderno de informação da saúde suplementar: beneficiários, operadoras e planos. 2017. Disponível em: <http://www.ans.gov.br/images/stories/ Materiais_para_pesquisa/Perfil_setor/Caderno_informacao_saude_suplementar/caderno_informacao_junho_2017.pdf>. Acesso em: 20 ago. 2018.

AGÊNCIA NACIONAL DE SAÚDE SUPLEMENTAR - ANS (Brasil). Relatório de atividades 2016. 2017. Disponível em: <http://www.ans.gov.br/images/stories/A_ANS/ Transparencia_Institucional/Prestacaode-Contas/Relatorio_de_Atividades/2016_relator io_atividades.pdf>. Acesso em: 20 ago. 2018.

ALVES, Daniele Conte; BAHIA, Ligia; BARROSO, André Feijó. O papel da Justiça nos planos e seguros de saúde no Brasil. Cadernos de Saúde Pública, Rio de Janeiro, v. 25, n. 2, p. 279-290, fev. 2009. 
ASENSI, Felipe Dutra. Judicialização ou juridicização? As instituições jurídicas e suas estratégias na saúde. Physis - Revista de Saúde Coletiva, Rio de Janeiro, v. 20, n. 1, p. 33-55, 2010.

BARROSO, Luis Roberto. A razão sem voto: o Supremo Tribunal Federal e o governo da maioria. Revista Brasileira de Políticas Públicas, Brasília, v. 5, Número Especial, p. 24-51, 2015.

BRITO, Fausto. A transição demográfica no Brasil: as possibilidades e os desafios para a economia e a sociedade. Belo Horizonte: UFMG/Cedeplar, 2007.

FREGAPANI, Guilherme Silva Barbosa. Formas alternativas de solução de conflitos e a lei dos juizados especiais cíveis. Revista de Informação Legislativa, Brasília, v. 34, n. 133, p. 99-107, jan./mar. 1997.

FUX, Luiz. Tutela de Urgência e Planos de Saúde. Rio de Janeiro: Espaço Jurídico, 2000.

GIBBONS, Robert. Game theory for applied economists. Princeton, EUA: Princeton University Press, 1992.

MAS-COLELL, Andreu et al. Microeconomic theory. New York, EUA: Oxford University Press, 1995.

NEVES, Pilar B. P.; PACHECO, Marcos Antônio B. Saúde pública e Poder Judiciário: percepções de magistrados no estado do Maranhão. Revista de Direito GV, São Paulo, v. 13, n. 3, p. 749-768, set./dez. 2017.

OCKÉ-REIS, Carlos O. Os desafios da ANS frente à concentração dos planos de saúde. Ciência \& Saúde Coletiva, Rio de Janeiro, v. 12, n. 4, p. 1041-1050, 2007.

OLIVEIRA, José A.D.; FORTES, Paulo A.C. De que reclamam afinal? Estudo de ações judiciais contra uma operadora de plano de saúde. Revista de Direito Sanitário, São Paulo, v. 13, n. 3, p. 33-58, nov./fev. 2013.

PINHEIRO, Armando Castelar; SADDI, Jairo. Direito, economia e mercados. São Paulo: Campus, 2005.

PRADO, Mariana M. The Debatable Role of Courts in Brazil's Health Care System: Does Litigation Harm or Help? Journal of Law, Medicine \& Ethics, v. 41, n. 1, p. 124-137, mar./jun. 2013.

RAMALHO, Bruno Araujo. A Interface institucional entre a ANS e o Poder Judiciário: análise de acórdãos sobre a cobertura de emergências médicas em planos de saúde. Revista De Direito Sanitário, São Paulo, v. 17, n. 1, p. 122-144, 2016.

RIBEIRO, Leandro Molhano; HARTMANN, Ivar A. A judicialização do direito à saúde e as mudanças institucionais no Brasil. In: PRADO, Mariana Mota (Org.). O Judiciário e o Estado Regulador brasileiro. São Paulo: FGV Direito SP, 2016.

ROBBA, Rafael. Judicialização dos planos e seguros de saúde coletivos no Tribunal de Justiça de São Paulo. Dissertação (Mestrado) - Faculdade de Medicina da USP, São Paulo, 2017.

SCHEFFER, Mário César. Coberturas assistenciais negadas pelos planos e seguros de saúde em ações julgadas pelo Tribunal de Justiça do Estado de São Paulo. Revista de Direito Sanitário, São Paulo, v. 14, n. 1, p. 122-132, mar./jun. 2013.

SILVA, Miriam Ventura da. O processo decisório judicial e a assessoria técnica: a argumentação jurídica e médicosanitária na garantia do direito à assistência terapêutica no Sistema Único de Saúde. Tese (Doutorado) Escola Nacional de Saúde Pública Sergio Arouca, Rio de Janeiro, 2012.

SUPERIOR TRIBUNAL DE JUSTIÇA. Recurso Especial no 1.657.156 / RJ, 2018. Disponível em: $<$ https://ww2.stj.jus.br/ processo/revista/inteiroteor/?num_regi stro=201700256297\&dt_publicacao $=04 / 05 / 2018>$. Acesso em: 02 set. 2018.

TRETTEL, Daniela Batalha. Planos de saúde na Justiça: o direito à saúde está sendo efetivado? Dissertação (Mestrado) - Faculdade de Direito da USP, São Paulo, 2009. 
TRETTEL, Daniela Batalha; KOZAN, Juliana Ferreira; SCHEFFER, Mário César. Judicialização em planos de saúde coletivos: os efeitos da opção regulatória da Agência Nacional de Saúde Suplementar nos conflitos entre consumidores e operadoras. Revista De Direito Sanitário, São Paulo, v. 19, n. 1, p. 166-187, 2018.

VIEIRA JUNIOR, Wilson M; MARTINS, Mônica. Idosos e planos de saúde no Brasil: análise das reclamações recebidas pela Agência Nacional de Saúde Suplementar. Ciência \& Saúde Coletiva, Rio de Janeiro v. 20, n. 12, p. 3817-3826, 2015. 
Para publicar na revista Brasileira de Políticas Públicas, acesse o endereço eletrônico www.rbpp.uniceub.br

Observe as normas de publicação, para facilitar e agilizar o trabalho de edição. 